\title{
Electrochemical, Photophysical, and Magnetic Properties of Green Emitting bis(2,5-Hexyloxy)-Phenylene-alt-Thiophene Fluorescent Conducting Oligomer Addended Fullerene-Diol Dyad
}

\author{
Rachana Singh $^{1}$, Rimpa Jaiswal ${ }^{2}$, Thakohari Goswami ${ }^{2 *}$ \\ ${ }^{1}$ School of Chemical and Biomolecular Engineering, Georgia Institute of Technology, Atlanta, USA \\ ${ }^{2}$ Electronics and Smart Materials Division, Defence Materials and Stores Research and Development Establishment, \\ Kanpur, India \\ Email: *thgoswami@yahoo.co.uk
}

Received September 18, 2013; revised October 25, 2013; accepted November 5, 2013

Copyright (C) 2013 Rachana Singh et al. This is an open access article distributed under the Creative Commons Attribution License, which permits unrestricted use, distribution, and reproduction in any medium, provided the original work is properly cited.

\begin{abstract}
Towards the development of potential new organic photovoltaic and optoelectronic materials, a simple route to synthesize flexibly ether linked fullerene-bis[oligo-(phenylene-alt-thiophene)] and evaluation of electrochemical, photophysi$\mathrm{cal}$ and magnetic properties is presented. Flexible ether linking of oligo-phenylene-thiophene chain to $1,2 \mathrm{C}_{60}(\mathrm{OH})_{2}$ is achieved employing Williamson's ether synthesis. 7-chain phenylene-thiophene chain fluorescent conducting oligomer is synthesized using Grignard coupling reaction with preservation of bromo end groups. Oligomer is highly ordered and soluble in all organic solvents while on linking to fullerene-diol, solubility of adduct restricts only to dimethyl sulfoxide (DMSO). All the synthesized materials are characterized through spectroscopic techniques and molecular weight is determined by mass spectrometry and GPC. Properties of the material indicate the substantial effect of fullerene. High quenching in fluorescence intensity and strong paramagnetic property are observed in this material.
\end{abstract}

Keywords: Fullerene-Diol; Fluorescent Conducting Oligomer; Electrochemical Properties; Photophysical Properties; Magnetic Properties

\section{Introduction}

Several fullerene-based donor-acceptor dyads [1-4] synthesized so far through the attachment of polymeric or oligomeric chain to fullerene have resulted in improved photovoltaic efficiency $[5,6]$. The search for flexibly attached donor moiety to fullerene core is, however, almost negligible. Ether linkages provide better flexibility and help in film formation. Away from conventional methods resulting in rigid cyclo-additions $[7,8]$, exohedral addition of hydroxyl groups on fullerene provides several sites for flexible attachment for other molecules [9-18]. Fullerenol behaves as excellent nucleophile because of the electrophilic nature of fullerene which makes hydroxyl hydrogen highly acidic. Interestingly, fullerenol is appeared to be very notorious owing to non-specified attachment of hydroxyl groups onto its surface but sup-

"Corresponding author. posed to be the most applicable molecule due to its high reactivity, stability and solubility. Controlled synthesis of fullerenol with fewer number of hydroxyl groups has opened up the way to use this magical derivative of fullerene and in the present study $1,2 \mathrm{C}_{60}(\mathrm{OH})_{2}$ used as the fullerene source [19]. Due to attachment of only two exohedral $\mathrm{OH}$ groups, fullerene's symmetry is not perturbed to a great extent and it preserves its high electrophilic character making the $\mathrm{C}_{60}(\mathrm{O})^{-2}$ efficient nucleophile.

One of the important issues to improve performance of photovoltaic material is to design donor moiety having effective donating capability. Extensive research is on to prepare different classes of donor molecules like polymers, macrocycles, etc., but polymers find most extensive application. Among the polymers, highly regioregular poly 3-hexylthiophene (rrP3HT) is being extensively used with the best results [20-22]. Substitution on the main chain and control over regio-regularity can tune the band 
gap of polythiophene from $1.0-2.5 \mathrm{eV}$ [22]. The lowest band gap allows the creation of polymer light-emitting diodes in the near infra red range and matches well with ultimate requirement for solar spectrum. The main drawback for commercial use of polymeric materials is, however, associated with their poor stability to air/oxygen resulting in larger off-currents \& lower on/off ratio and also positive shift in the threshold voltage in case of organic thin film transistor (OTFTs). The stability towards oxidative doping is related to ionization potential, i.e., the highest occupied molecular orbital (HOMO) levels in vacuum and lowering of HOMO-level improves its stability. This can be achieved by a number of methods. Introduction of electron donating groups, such as alkoxy or thio-alkyl groups, at $\beta$-position of thiophene unit increases the band gap by lowering HOMO level $[23,24]$. Insertion of suitably substituted phenylene rings into the thiophene backbone is another efficient structural modification approach for improving photoluminescence (PL) efficiency of thiophene-based conjugated polymers [25]. Substitutions on both phenylene and thiophene rings remarkably affect the PL quantum efficiency of the resulting polymers and also provide better air stability.

Present article describes a simple and convenient method for stepwise synthesis of regioregular bromo end capped 7-chain phenylene-alt-thiophene oligomer (5) and its further attachment to 1,2-fullerene-diol to achieve novel photovoltaic materials (6). One of the strong advantages of this synthesis route is that the use of both cryogenic temperatures and highly reactive metals is not required and consequently this method offers quick and easy preparation of oligomer in large scale. These reactions are carried out either at room temperature or in reflux condition. Covalent attachment of $\mathbf{5}$ onto fullerene core by nucleophilic substitution of the terminal bromo group with the hydroxyl groups of fullerenol produces fullerenol-adduct 6 . Evaluation of thermal, photophysical and magnetic properties of the material indicates substantial effect of fullerene on the thermal behavior as well as high quenching in fluorescence intensity and strong paramagnetic property.

\section{Experimental Section}

\subsection{Materials}

[60] fullerene was obtained from MER Co. (purity > $99.5 \%$ ). The sample quality was checked by UV/vis absorption, ${ }^{13} \mathrm{C}$ NMR, and was used without further purification. Thiophene and hydroquinone were purchased from E Merck and used without further purification. NBS was recrystallized and dried freshly. All solvents were purified and dried before use. All glass wares were flame dried under argon before reaction.

\subsection{Synthesis of Monomer Units}

\subsubsection{Synthesis of Diiodothiophene (1)}

In a $200 \mathrm{~mL}$ three necked flask, $4.2 \mathrm{~g}(0.05 \mathrm{M})$ of thiophene is added into $30 \mathrm{~mL}$ DCM. $64.5 \mathrm{~g}$ of iodine $(0.25$ $\mathrm{M})$ is added in portions with high speed stirring (mechanical). A solution of $68 \mathrm{~mL}$ nitric acid: water (1:1) is transferred to a dropping funnel fitted to the flask and $\sim 10 \mathrm{~mL}$ of this nitric acid: water mixture is added slowly with vigorous stirring. Once initiated, the reaction proceeds vigorously with the evolution of brown oxides of nitrogen. After the evolution of gases is subsided, the remaining nitric acid is added drop wise and reaction proceeds smoothly at room temperature. After all nitric acid is added, the solution is heated under refluxing for $30 \mathrm{~min}$. The reaction mixture is allowed to stand and the red organic layer is collected and washed several times with water and dried over anhy. $\mathrm{Na}_{2} \mathrm{SO}_{4}$ and concentrated to yellow oil. On cooling the yellow oil freezes and collected as yellow crystals of diiodothiophene. The product is characterized by ${ }^{1} \mathrm{H} \&{ }^{13} \mathrm{C} \mathrm{NMR}\left(\mathrm{CDCl}_{3}, \delta\right)$; a singlet at $6.96 \mathrm{ppm}$ for the two thiophene ring protons and two carbon peaks at $78 \& 138 \mathrm{ppm}$ for substituted and unsubstituted thiophene carbons respectively clearly supporting the formation of 1,5-diiodothiophene. UV-vis (methanol, nm) 242, 245, 252, $256 \& 266$; Yield $=50 \%$, mp: $37^{\circ} \mathrm{C}$.

\subsubsection{Synthesis of 1,4 Dihexyloxy Phenylene (2)}

To the degassed alkaline (12.5 $\mathrm{g} \mathrm{NaOH})$ methanolic solution of hydroquinone $(11 \mathrm{~g}, 100 \mathrm{mM}$ in $150 \mathrm{~mL}$ methanol), 1-bromo hexane (35.09 $\mathrm{mL}, 250 \mathrm{mM})$ is added slowly at room temperature. The reaction mixture is then refluxed for $24 \mathrm{~h}$ and finally extracted with diethyl ether (4 times, $50 \mathrm{~mL}$ each). Combined organic fractions were washed with $10 \% \mathrm{NaOH}$ solution $(2-3$ times; $50 \mathrm{~mL}$ each) and further with water to remove the impurity of hydroquinone and alkali respectively. Organic layer is dried over anhy. $\mathrm{Na}_{2} \mathrm{SO}_{4} \&$ concentrated to obtain white crystals. Washed several times with chilled methanol and further re-crystallized with dicholomethane. ${ }^{1} \mathrm{H}$ NMR $\left(\mathrm{CDCl}_{3}, \delta\right) 0.8\left(\mathrm{t}, 6 \mathrm{H}, \mathrm{CH}_{3}\right), 1.2(\mathrm{~m}, 8 \mathrm{H}$, $\mathrm{CH}_{2} \mathrm{CH}_{2}$ ), 1.3 (q, 4H, $\mathrm{CH}_{2}$ ), 1.6 (q, 4H, $\mathrm{CH}_{2}$ ), 3.8 (t, $4 \mathrm{H}$, $-\mathrm{O}-\mathrm{CH}_{2}$ ), 6.7 (s, 4H, Ph); UV-vis (methanol, nm) 227, 248, 254, $260 \& 290$; Yield $=55 \%$, mp: $36^{\circ} \mathrm{C}$.

\subsubsection{Synthesis of 1,4 Dibromo-2,5 \\ Dihexyloxy Phenylene (3)}

To a mixture of $\mathrm{CH}_{2} \mathrm{Cl}_{2} / \mathrm{CH}_{3} \mathrm{COOH}(100 \mathrm{~mL}, 1: 1)$ solution, $2(5 \mathrm{~g}, 0.018 \mathrm{M})$ is added under inert atmosphere and stirred for $15 \mathrm{~min}$. N-bromo succinimide (NBS) is added in portions $(5.3 \mathrm{~g}, 0.045 \mathrm{M})$ with stirring. Reaction temperature is raised to $60^{\circ} \mathrm{C}$ in stirring condition on complete addition of NBS. After $24 \mathrm{~h}$ of stirring the re- 
action mixture is poured onto $200 \mathrm{~mL}$ water. Organic layer is separated and washed 3 - 4 times with $100 \mathrm{~mL}$ saturated sodium sulphate solution \& further washed with water. Organic layer is dried over anhy. $\mathrm{Na}_{2} \mathrm{SO}_{4}$ \& concentrated. Pinkish-white colored crystals are obtained and recrystallized with dichloromethane. ${ }^{1} \mathrm{H}$ NMR $\left(\mathrm{CDCl}_{3}, \delta\right): 0.8\left(\mathrm{t}, 6 \mathrm{H}, \mathrm{CH}_{3}\right), 1.2\left(\mathrm{~m}, 18 \mathrm{H}, \mathrm{CH}_{2} \mathrm{CH}_{2}\right), 1.3$ (q, 4H, $\left.\mathrm{CH}_{2}\right), 1.6$ (q, 4H, $\left.\mathrm{CH}_{2}\right), 3.8\left(\mathrm{t}, 4 \mathrm{H},-\mathrm{O}-\mathrm{CH}_{2}\right), 7.06$ (s, 2H, Ph); UV-vis (methanol, nm) 227, 248, 254, 260 \& 29; Yield $=67 \%$, mp: $50^{\circ} \mathrm{C}$.

\subsubsection{Synthesis of 4}

1) Preparation of Grignard Reagent of Diiodothiophene: Few drops of mixture of diiodothiophene (1, $1.0078 \mathrm{~g}, 3 \mathrm{mM})$ and dry dichloro-ethane $(1.437 \mathrm{~mL}, 18$ $\mathrm{mM})$ in $30 \mathrm{~mL}$ dry THF is added to the dry $\mathrm{Mg}(0.18023$, $7.5 \mathrm{mM})$ also in dry THF $(20 \mathrm{~mL})$ under inert atmosphere at refluxing temperature $\left(65^{\circ} \mathrm{C}-70^{\circ} \mathrm{C}\right) .1 \mathrm{~mL}$ of dry dichloro-ethane is further added to initiate the reaction. After initiation, the rest of the diiodothiophene/dichloro-ethane solution is added drop wise over $1 \mathrm{~h}$. Reaction mixture is refluxed for $5 \mathrm{~h} \&$ cooled to room temperature.

2) Grignard coupling reaction: The Grignard of 1 thus prepared, is slowly transferred to the ice-cooled dry THF solution of 3 (3.48 g, $7.5 \mathrm{mM}$ ) and $\mathrm{Ni}$ (dppe) $\mathrm{Cl}_{2}$ $(30 \mathrm{mg})$ was added under inert atmosphere with stirring at room temperature. After $24 \mathrm{~h}, 50 \mathrm{~mL}$ of saturated ammonium chloride solution is added and stirred for 30 min. Organic layer is washed several times with water and dried over anhy. $\mathrm{Na}_{2} \mathrm{SO}_{4}$ and concentrated to $2 \mathrm{~mL}$. The concentrate is kept in refrigerator for crystallization. The obtained crystals are further recrystallized with dichloromethane. The FTIR $\left(\mathrm{KBr}, \mathrm{cm}^{-1}\right) 3050(v,=\mathrm{C}-\mathrm{H})$, 2919, 2848 ( $v, \mathrm{C}-\mathrm{H}), 1676(v, \mathrm{C}=\mathrm{C} \mathrm{Ph}), 1495(v, \mathrm{C}=\mathrm{C}$ Th), 1462, 1393, $1358\left(\delta, \mathrm{CH}_{3}\right), 1269,1210\left(\delta, \mathrm{CH}_{2}\right)$, 1124 ( $v, \mathrm{C}-\mathrm{Br}), 1062$ ( $v,=\mathrm{C}-\mathrm{O}), 1020$ ( $v, \mathrm{C}-\mathrm{O}$ ether), 805 $\& 726(\delta$, out of plane $=\mathrm{C}-\mathrm{H})$. NMR $\left({ }^{1} \mathrm{H} \&{ }^{13} \mathrm{C}, \mathrm{CDCl}_{3}\right.$, d) 0.8 - $0.9,1.34$ - 1.36, 1.45 - 1.52, 1.75 - 1.85, 3.93 $3.97,6.8,6.9,7.09 ; 13.9,22.5,25.5,28.9,31.4,70.19$, 111.0, 114.2, 118.3, 119.3, 149.9; UV-vis (methanol, nm) $249,255 \& 300 ;$ Yield $=2 \mathrm{~g}(83 \%) ; \mathrm{mp}=50^{\circ} \mathrm{C}$.

\subsubsection{Synthesis of 7-Chain Oligomer (5)}

Grignard of 1 (0.3359 g, $1 \mathrm{mM})$, prepared as described above, is added to the ice-cooled dry THF solution of 4 (2 g, $2.5 \mathrm{mM}$ ) and $\mathrm{Ni}$ (ddpe) $\mathrm{Cl}_{2}(30 \mathrm{mg}$ ) under inert atmosphere in stirring condition. Temperature is raised to $r$. $\mathrm{t}\left(25^{\circ} \mathrm{C}\right)$ and stirring continued for $24 \mathrm{~h}$. Similar work-up steps to that of product 4ii are employed and is recrystallized with dichloromethane. FTIR ( $\left.\mathrm{KBr}, \mathrm{cm}^{-1}\right) 3000(v$, $=\mathrm{C}-\mathrm{H}), 2932,2848(v, \mathrm{C}-\mathrm{H}), 1677(v, \mathrm{C}=\mathrm{C} \mathrm{Ph}), 1495(v$, $\mathrm{C}=\mathrm{C}$ Th $), 1462,1394,1359\left(\delta, \mathrm{CH}_{3}\right), 1269,1210(\delta$, $\left.\mathrm{CH}_{2}\right), 1124$ ( $\left.v, \mathrm{C}-\mathrm{Br}\right), 1062$ ( $\left.v,=\mathrm{C}-\mathrm{O}\right), 1020$ ( $v, \mathrm{C}-\mathrm{O}$ ether), $805 \& 726(\delta$, out of plane $=\mathrm{C}-\mathrm{H}) .{ }^{1} \mathrm{H} \&{ }^{13} \mathrm{C} \mathrm{NMR}$ $(\mathrm{CDCl} 3, \delta) 0.8$ - 0.9, 1.22, 1.6, 1.7, 3.8, 6.7 - 6.8, 6.8, $7.01 ; 13.9,22.3,25.3,29.1,31.2,70.2,111,112,114$, 118, 119, 138, 150, 153. UV-vis (methanol, nm) 249, $255 \& 300 ;$ Yield $=2 \mathrm{~g}(66 \%) ; \mathrm{mp}=55^{\circ} \mathrm{C}$.

\subsubsection{Synthesis of Fullerene-Oligomer Adduct (6)}

To the benzene solution of fullerenol $(0.020 \mathrm{~g}, 0.027$ $\mathrm{mM}$ ), $\mathrm{K}_{2} \mathrm{CO}_{3}$ (anhy, $0.0398 \mathrm{~g}, 2.88 \mathrm{mM}$ ) and 18-crown6 -ether (catalytic amount) are added at room temperature $\left(25^{\circ} \mathrm{C}\right)$. The benzene solution of oligomer 5 (0.2177 g, $1.44 \mathrm{mM}$ in $10 \mathrm{~mL}$ ) is added drop wise with stirring at room temperature. The temperature of the reaction mixture is now raised to reflux and after $24 \mathrm{~h}$ of refluxing; the solid mass is collected by centrifugation and washed several times with methanol: water $(80: 20)$ mixture to remove the impurity of $\mathrm{K}_{2} \mathrm{CO}_{3}$ and crown ether. Solid dried and collected.

Yield $=10 \mathrm{mg}(50 \%)$; FTIR $\left(\mathrm{KBr}, \mathrm{cm}^{-1}\right) 3187(v$, $=\mathrm{C}-\mathrm{H}), 2932,2849(v, \mathrm{C}-\mathrm{H}), 1656(v, \mathrm{C}=\mathrm{C} \mathrm{Ph}), 1495(v$, $\mathrm{C}=\mathrm{C}$ Th$), 1451,1376\left(\delta, \mathrm{CH}_{3}\right), 1104(v, \mathrm{C}-\mathrm{Br}), 1020(v$, $\mathrm{C}-\mathrm{O}$ ether $), 805 \& 726(\delta$, out of plane $=\mathrm{C}-\mathrm{H}) ;{ }^{1} \mathrm{H} \&{ }^{13} \mathrm{C}$ NMR (DMSO, $\delta$ ) 0.8 - 1.0, 1.15 - 1.23, 1.6, 2.3, 3.4 - 3.5, 7.16 - 7.18, 7.23 - 7.25; 21, 29, 30, 33, 34, 69.8, 125.6, $128.5,129.2,130.08,148.3,150.9,156.2$.

\section{Results and Discussion}

\subsection{Synthesis and Identity of Products}

A simple approach towards the synthesis of highly ordered oligomeric chain has been adopted starting with 2,5 diiodo thiophene (1) prepared by reported method (Scheme 1). Grignard coupling of (1') and 1,4 dibromo 2,5-bis hexyloxy benzene (3) results in 3-chained 2,5-bis (4-bromo-2,5(hexyloxy) phenyl) thiophene (4). Repetition of the above reaction using (4) and Grignard of (1) converts (4) into oligomer (5) (Scheme 2) retaining terminal bromo groups. The conversion efficiency of the Grignard coupling is excellent (83\%). All materials have been purified by flash chromatography. Selective attachment of the regioregular oligomer to fullerene core in heterogeneous medium is carried out using benzene solution of fullerene-diol and oligomer (5) with $\mathrm{K}_{2} \mathrm{CO}_{3}$ in presence of 18-crown-6-ether. Refluxing for $24 \mathrm{~h}$ yields dyad (6) in good yield (Scheme 3). 1,2 $\mathrm{C}_{60}(\mathrm{OH})_{2}$ has been synthesized and purified according to reported method [19].

Oligomer (5) is a pale yellow crystalline solid soluble in most of the organic solvents, while the dyad (6) is black powder with solubility only in DMSO.

Product structures are established by spectroscopic characterization. The critical ${ }^{13} \mathrm{C}$ peaks assignment of the oligomer (5) suggest three non equivalent carbons $\left(\mathrm{C}_{1}\right.$, $\mathrm{C}_{2}, \mathrm{C}_{3}$ ) for inner phenylene ring and six for terminal 


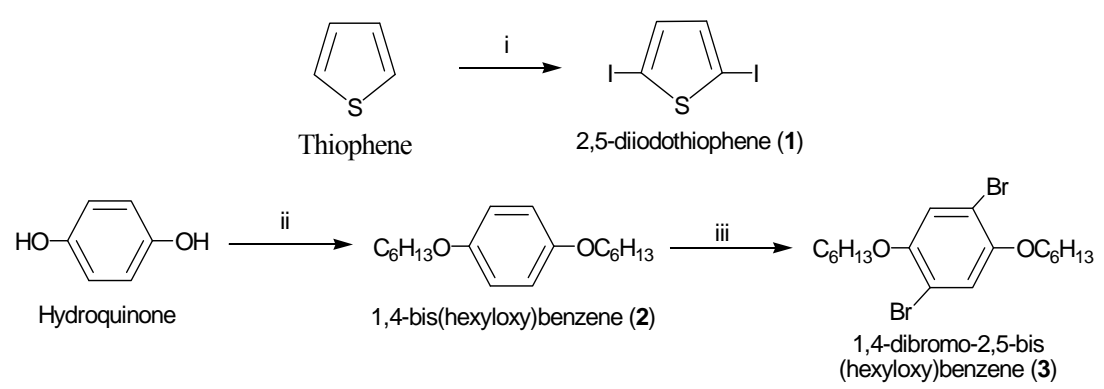

Scheme 1. Synthesis of precursor materials $1 \&$ 3. (i) Iodine $(0.25 \mathrm{M})$, Nitric acid : water $(1: 1,68 \mathrm{~mL})$, refluxed for $30 \mathrm{~min}$; (ii) NaOH (12.5 g), 1-bromo hexane (0.25 M), refluxed for 24 h; (iii) CH2Cl2/CH3COOH (100 mL, 1:1), 2 (0.018 M), NBS (0.045 $\mathrm{M}), 24 \mathrm{~h}$ stirring at $60^{\circ} \mathrm{C}$.

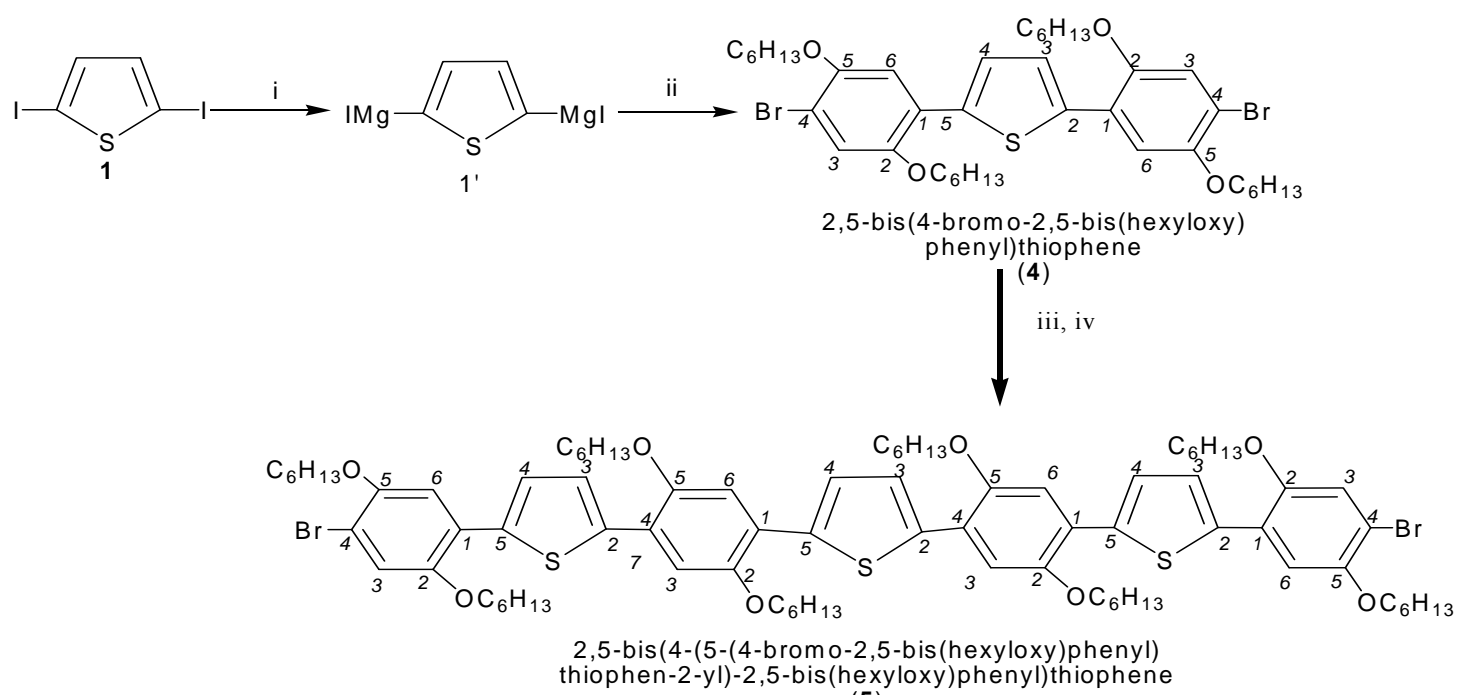

(5)

Scheme 2. Synthesis of precursor materials $4 \&$ oligomer 5. (i) Dichloro ethane $(18 \mathrm{~mL}), \mathrm{Mg}(7.5 \mathrm{mM})$, refluxed at $65^{\circ} \mathrm{C}-$ $70^{\circ} \mathrm{C}$ for $5 \mathrm{~h}$; (ii) THF solution of 3 (7.5 mM), Ni (dppe) $\mathrm{Cl}_{2}$ (30 mg), stirred for $24 \mathrm{~h}$, (iii) 1'; (iv) Ni (dppe) $\mathrm{Cl}_{2} / 24 \mathrm{~h} \mathrm{stirring} / \mathrm{r}$. t.

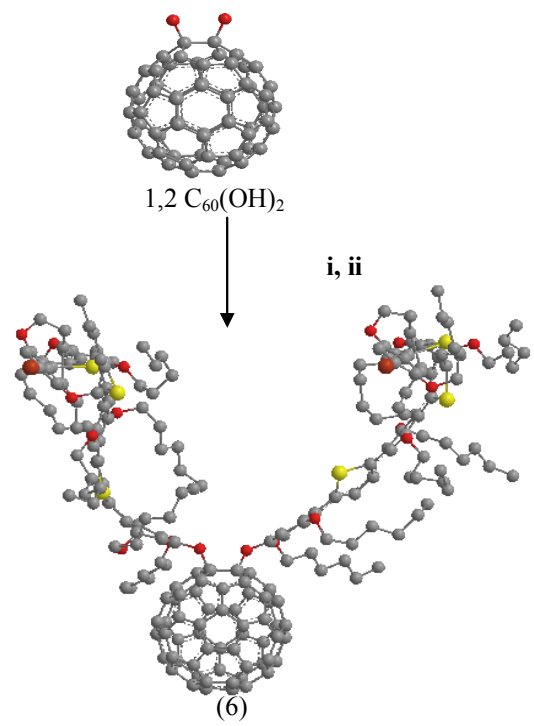

Scheme 3. Outline of reaction scheme for the synthesis of phenylene-alt-thiophene addended fullerenediol dyad (6). (i) $\mathrm{K}_{2} \mathrm{CO}_{3}(2.88 \mathrm{mM})$, 18-Crown-6-Ether; (ii) Benzene solution of $5(1.44 \mathrm{mM}), 24 \mathrm{~h}$ refluxing. phenyl ring, of which $\mathrm{C}_{1}$ and $\mathrm{C}_{2}$ is common for both. Thiophene has two non-equivalent carbons $\left(C_{2}, C_{3}\right)$. Overall one should expect eight ${ }^{13} \mathrm{C}$ peaks for (5). On the other hand, ${ }^{1} \mathrm{H}$ NMR assigns four types of non-equivalent protons; inner phenyl ring proton at $\mathrm{C}_{3}$, two different protons for the terminal ring at $\mathrm{C}_{3}$ and $\mathrm{C}_{6}$ and single proton for thiophene at $\mathrm{C}_{3}$. The FTIR spectrum of (5) also nicely accords with the proposed structure. The inter-ring $\mathrm{C}-\mathrm{C} \& \mathrm{C}-\mathrm{Br}$ streching peak is appearing in product (5). The molecular weight of the oligomer estimated by GPC using polystyrene as standard confirms the 7-ringed oligomeric phenylene-thiophene structure with poly-dispersity $\sim 1.1$. The molecular ion peak in ESI-MS (methanol, $\mathrm{M}^{+}-1$ at $\mathrm{m} / \mathrm{z} 1521$ ) also adheres with the GPC result.

Attachment of oligomer to fullerene core is evident from the disappearance of all the typical peaks of fullerenol and appearance of aromatic \& alkyl stretching and bending peaks in FTIR spectrum of (6). The spectrum also shows peak for $\mathrm{C}-\mathrm{Br}(v)$ at $1104 \mathrm{~cm}^{-1}$ suggesting single terminal bromo group involvement in the reaction. Fol-O-C ether linkage is ascertained from the ap- 
pearance of broad $(v)$-band at $1020 \mathrm{~cm}^{-1}$. All eight non-equivalent carbon peaks, similar to that of (5), still exist in ${ }^{13} \mathrm{C}$ NMR of the dyad (6). The broad peaks in ${ }^{1} \mathrm{H}$ NMR are shifted down-field due to the attachment of electronegative fullerene into oligomer. $\mathrm{Sp}^{3}$ hybridized fullerene (at the point of attachment) as well as hexyloxy carbon peaks are present. High symmetry of the dyad is as well be determined by NMR spectroscopy. Broad triplet for methyl group of hexyloxy chain, followed by methylene proton peaks between 2.2 - 2.6 ppm are observed in ${ }^{1} \mathrm{H}$ NMR of (6). Appearance of single triplet for methylenoxy protons envisaged the equivalent nature of the addend oligomeric chain. Aromatic proton peaks appear between 7.1 - $7.3 \mathrm{ppm}$. Due to paramagnetic nature of the dyad material, NMR signals are not very sharp.

\subsection{Molecular Modeling}

Effect of exohedral addition of OH-groups in fullerenol and oligomers in dyad is compared with that of fullerene by performing molecular modeling at semiemperical AM1 level using DS visualizer (Figure 1) and with SPARTAN for the lowest energy molecule (1597.3744 $\mathrm{Kcal} / \mathrm{mol}$ ) (Figure 2). $\mathrm{C}_{1}-\mathrm{C}_{2}$ bond length of fullerene moiety in derivatives has increased due to addition. Molecular modeling calculation measures $\mathrm{C}_{1}-\mathrm{C}_{2}$ bond length of $1.55-1.609 \AA$ in diol to compared to $1.38 \AA$ in pristine fullerene suggesting conversion of $\mathrm{sp}^{2}$ carbon into $\mathrm{sp}^{3}$. A further nominal increment by ca. $0.03 \AA$. of $\mathrm{C}_{1}-\mathrm{C}_{2}$ bond length has been observed on addition of oligomeric chain. Slight change in bond angle is also observed on oligomer addition.

\subsection{Thermal Properties}

Oligomer $\mathbf{5}$ is a crystalline solid material possessing good

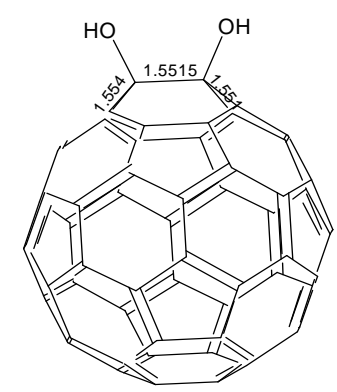

(a)

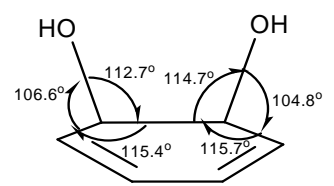

(c)

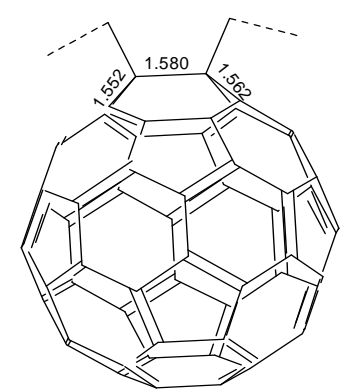

(b)

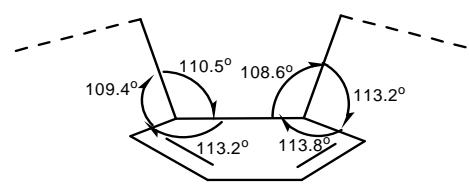

(d)
Figure 1. Semiemperical AM1 molecular modeling using DS visualizer for comparison of bond length ((a) \& (b), $\AA$ ) and bond angles ((c) \& (d)) between fullerene-diol and dyad (6).

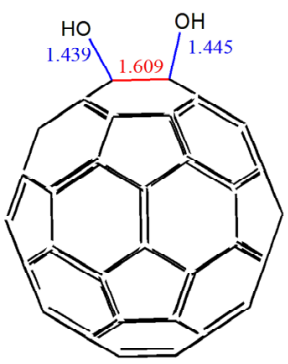

(a)

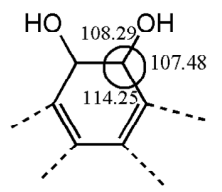

(c)

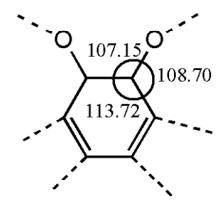

(e)

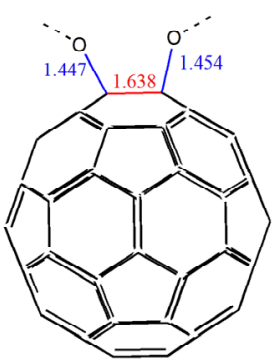

(b)

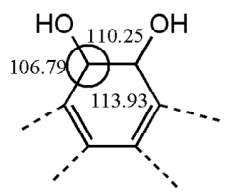

(d)

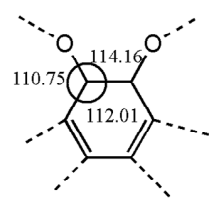

(f)
Figure 2. Molecular modeling with SPARTAN for the lowest energy molecule (1597.3744 $\mathrm{Kcal} / \mathrm{mol})$ for comparison of bond length $(\AA)$ and bond angles (degree) between fullerenediol and dyad (6).

thermal stability. Melting point recorded in DSC is reported to be $64.2^{\circ} \mathrm{C}$ and the enthalpy of melting $\left(\Delta H_{m}\right)$ is $121.6 \mathrm{~J} / \mathrm{g}$ (Figure 3). The oligomer (heating rate of $10^{\circ} \mathrm{C} / \mathrm{min}$ in nitrogen atmosphere) shows thermal stability up to $150^{\circ} \mathrm{C}$ followed by a sharp degradation. First derivative TGA trace indicate single degradation step (crest temp $318.4^{\circ} \mathrm{C}$ ) owing to high symmetric structure. It is attributed to the formation of more rigid planar interdigited $\pi$-stack 3D structure and conformational symmetry due to thermal ordering of hexyloxy groups attached in regular fashion at a particular distance. Flexible ether linkages of hexyloxy groups might have assisted in attending such geometry.

Symmetric structure of $\mathbf{5}$ is perturbed on chemical attachment to fullerene and is clearly evident from the TGA and first derivative TGA thermogram of $\mathbf{6}$. Adduct 6 still maintain initial thermal stability up to $150^{\circ} \mathrm{C}$ and the small weight loss $(6.7 \%)$ within this temperature range is due to removal of low boiling solvents physically absorbed on the surface. Stepwise removal of addended oligomers is also recorded in first derivative before the structural degradation of fullerene. First step is associated with long temperature zone $150^{\circ} \mathrm{C}-410^{\circ} \mathrm{C}$ (crest temp $330.78^{\circ} \mathrm{C}$ ) followed by two sharp steps in the temperature range $425^{\circ} \mathrm{C}-520^{\circ} \mathrm{C}$ (crest temperature $480.16^{\circ} \mathrm{C}$ ) and $520^{\circ} \mathrm{C}-560^{\circ} \mathrm{C}$ (crest temperature $550^{\circ} \mathrm{C}$ ) respectively (Figure 4). Weight loss associated with each step corresponds to sequential release of terminal bromo 


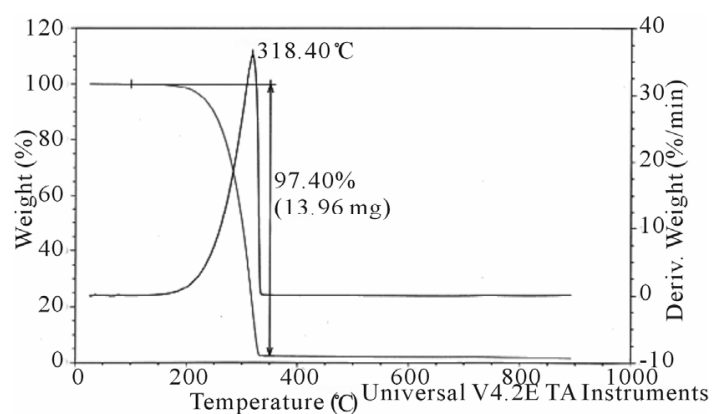

(a)

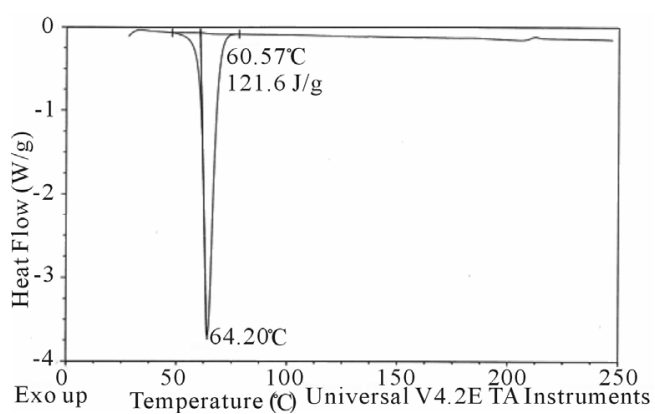

(b)

Figure 3. (a) TGA and (b) DSC of oligomer 5 recorded under inert atmosphere and at heating rate of $10^{\circ} \mathrm{C} / \mathrm{min}$.

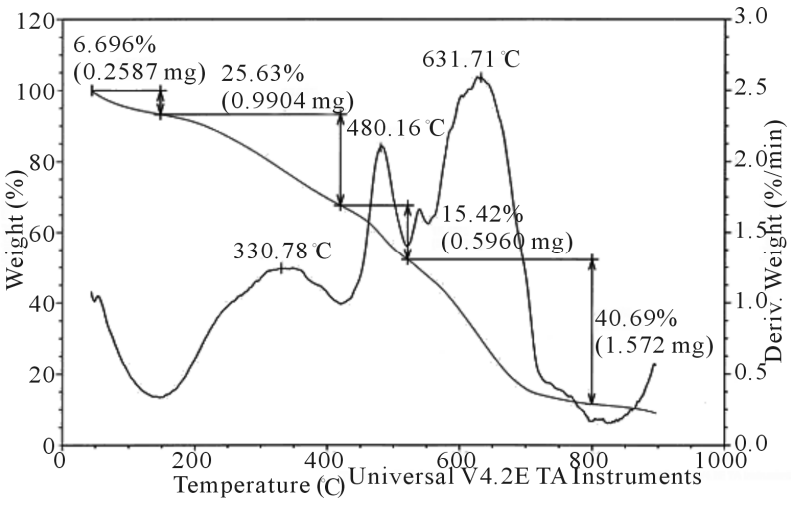

(a)

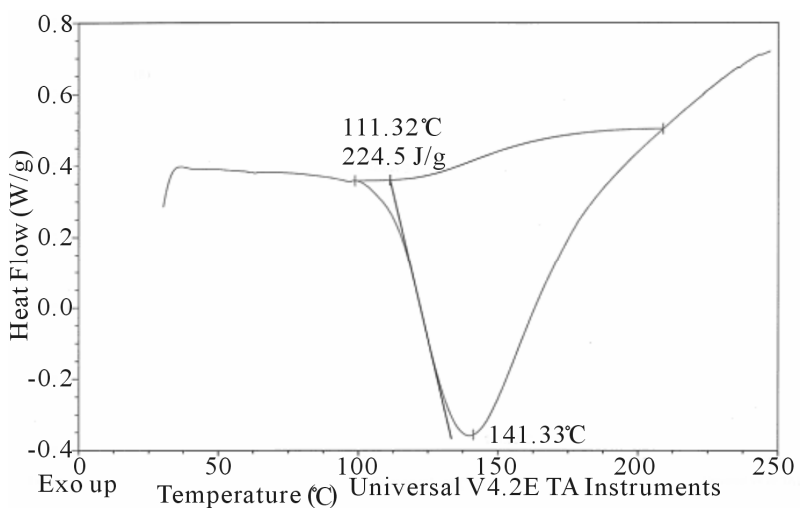

(b)

Figure 4. (a) TGA and (b) DSC of adduct 6 recorded at a heating rate of $10^{\circ} \mathrm{C} / \mathrm{min}$ under $\mathrm{N}_{2}$ atm.

Containing phenylene and attached thiophene ring followed by middle phenylene and thiophene rings respectively. The required amount of absorbed energy associated during sequential release of addended aromatic units is calculated to be $224.5 \mathrm{~J} / \mathrm{g}$ (DSC of 6 in $\mathrm{N}_{2}$ atm., heating rate $\left.10^{\circ} \mathrm{C} / \mathrm{min}\right)$.

\subsection{Electrochemical Properties}

Cyclic voltammograms are recorded with a computer controlled Autolab model 302 Potentiostat at a constant scan rate of $25 \mathrm{mV} / \mathrm{s}$ using $0.1 \mathrm{M}$ tetrabutyl ammonium perchlorate $\left(\mathrm{n}-\mathrm{Bu}_{4} \mathrm{NH}_{4} \mathrm{ClO}_{4}\right)$ in acetonitrile as supporting electrolyte. A three-electrode configuration undivided cell is used: platinum disc working electrode, platinum wire counter electrode and $\mathrm{Ag} / \mathrm{AgCl}(3 \mathrm{M} \mathrm{KCl}$ and saturated $\mathrm{Ag} / \mathrm{Cl}$ ) separated with a diaphragm as reference electrode. Typical cyclic voltammogram of 5 (scans window between -1.2 to $2.0 \mathrm{~V}$ ) is displayed in Figure 5 and the electrochemical data are presented in Table $\mathbf{1 .}$ Formal reduction potential $\left[E_{\text {red }}=\left(E_{\mathrm{pa}}+E_{\mathrm{pc}}\right) / 2\right]$ is $-0.77 \mathrm{~V}$ and the onset reduction potential $\left(E_{\text {red }}^{0}\right)$ is recorded to be $-0.66 \mathrm{~V}$. Values of formal oxidation potential $\left(E_{\mathrm{ox}}\right)$ and onset oxidation potential $\left(E_{\mathrm{ox}}^{0}\right)$ are similarly measured to be $1.42 \mathrm{~V}$ and $1.47 \mathrm{~V}$ respectively. The measured redox behavior is transposed to estimate the ionization potential $\left(I_{p}\right)$ and electron affinity $\left(E_{a}\right)$ using an empirical relationship proposed by Bredas et al. [26]

$$
I_{p}=\left(E_{\mathrm{ox}}^{0}+4.4\right) \mathrm{eV}
$$

and

$$
E_{a}=\left(E_{\text {red }}^{0}+4.4\right) \mathrm{eV}
$$

where $E_{\mathrm{ox}}^{0}$ and $E_{\mathrm{red}}^{0}$ are the onset potentials for oxidation and reduction relative to $\mathrm{Ag} / \mathrm{AgCl}$ reference electrode from vacuum level. [27] Electron affinity (LUMO level) and ionization potential (HOMO level) is calculated as $3.74 \mathrm{eV}$ and $5.87 \mathrm{eV}$ and the difference in energy between $I_{p}$ and $E_{a}$ yields the band gap of the material. For 5 , the value is $2.13 \mathrm{eV}$.

The measured low band gap value in $\mathbf{5}$ compared to pristine oligo-thiophene and oligo-phenylene analogues suggest a more regular structure in solution and incorporation of alkoxy substituted phenylene ring alternate to each thiophene can be a better design for obtaining these $\pi$-conjugated systems. Reports suggest that for thiophene-phenylene oligomers, the standard formal oxidation potential $\left(E_{\mathrm{ox}}\right)$ increases with the introduction of p-phenylene rings into the oligomer [28]. This increase in oxidation potential is ca $0.15 \mathrm{~V}$ for one p-phenylene ring and subsequent introduction of p-phenylene rings shift its oxidation potential by ca. $0.10 \mathrm{~V}$. It means that the thio- 


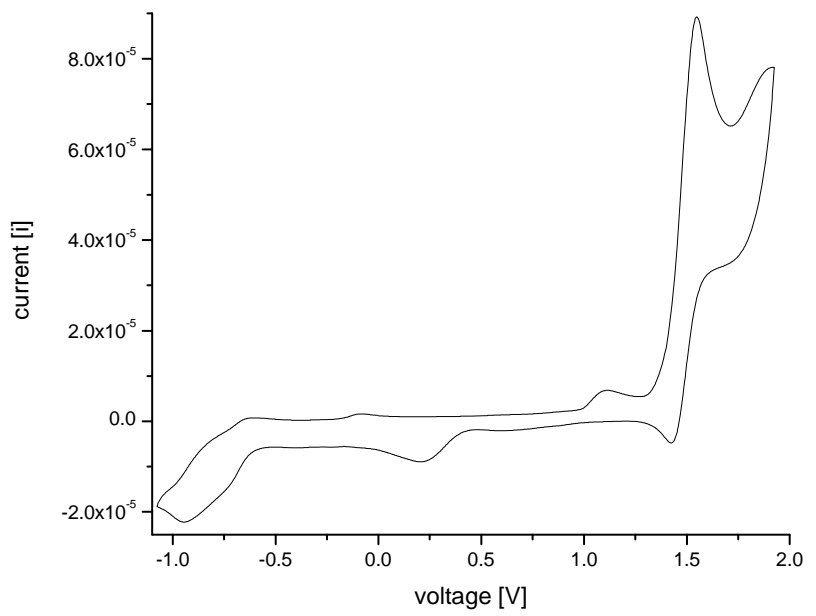

Figure 5. Cyclic voltammogram of oligomer $5(3 \mathrm{mM}$ in acetonitrile) recorded at $25^{\circ} \mathrm{C}$ using sweep rate of $25 \mathrm{mV} \cdot \mathrm{s}^{-1}$

phene-phenylene oligomer (5) should have better air stability than the corresponding oligo-thiophenes. Electrochemical properties of fol-adduct (6) could not be measured due to solubility problem of the material. Operating window of DMSO falls in the range -1 to $+1 \mathrm{~V}$ and the adduct (6) does not show any characteristic redox peak in this range.

\subsection{Photophysical Properties}

Electrical and optical properties of phenylene-thiophene copolymers mainly depend on mean conjugation chain length and $\pi$-electron delocalization $[29,30]$. The nature of the substituted group generally affects the electronic and optical properties of the conjugated polymers in two ways [31]; the electronic feature of the substituted group and steric hindrance arising from the substituted group. The side chains do not take part directly in the $\pi$-bonds delocalization, but their steric hindrance could induce a considerable inter-ring twisting, giving rise to a substantial reduction of conjugation length. It has been demonstrated both experimentally and theoretically that alkyl substitution in polythiophene gives rise to stronger steric hindrance and increases the torsional angles between aromatic rings (effectively reduces conjugation length) resulting spectral blue shift in absorption [32]. On the other hand, introduction of alkoxy chains at 2- and 5positions of the phenylene rings induces spectral red shift of the same polymers [33-35]. Strong electron-donating property and less steric hindrance of alkoxy groups compared to alkyl substituents are considered responsible for the spectral red shift and by far, hexyloxy substituents at 2,5-position of phenylene rings have the highest effect on spectral red shift [33]. Theoretical works [36] on the copolymers suggest that the resultant band gap is the weight average band gap value of the individual unit in polymer composed of alternative low (i.e., thiophene) and high (i.e., phenylene) band gap materials. Experi- mental observation records $20-40 \mathrm{~nm}$ blue shifts of the absorption maxima (higher energy) in dilute chloroform solution on inserting a single phenylene unit in 5-ring polymer of thiophene analogue [28].

\subsubsection{Absorption Properties}

Absorption spectrum of (4) in chloroform at room temperature $\left(25^{\circ} \mathrm{C}\right)$ shows maxima at $302 \mathrm{~nm}$ which is appreciably red-shifted (lower energy) compared to their individual building blocks (1) and (3) because of easy $\pi-\pi^{*}$ transition on increasing the conjugated chain length. A blue-shift (higher energy) in absorption maxima by about $50 \mathrm{~nm}$ compared to 3-ring thiophene homologue (Table 2) is indeed observed. The optical-gap calculated from absorption edge (absorption onset;

$\lambda_{\text {onset }}=326 \mathrm{~nm} / 3.83 \mathrm{eV}$ ) is substantially higher than its thiophene homologue. The result suggests that the presence of p-phenylene groups does not break delocalization but do influence their HOMO-LUMO optical band gap. The absorption maxima of 7-chain oligomer (5) remains the same $\left(\lambda_{\max }=302 \mathrm{~nm}\right)$ although optical-gap is slightly reduced (Abs $\left.\lambda_{\text {onset }}=340 \mathrm{~nm} / 3.66 \mathrm{eV}\right)$ on increasing the chain length from 3 to 7 (Figure 6). This result indicates that the absorption maxima remains uneffected on inserting 1,4-hexyloxy substituted phenylene group between two thiophene units, although optical gap is slightly decreased by ca. $0.17 \mathrm{eV}$. The optical gap is however significantly higher compared to 7-ring thiophene homo-polymer $(\sim 2.8 \mathrm{eV})$ and the difference is about $0.8 \mathrm{eV}$ and the optical band gap is more comparable to 7-ring oligo $p$-phenylene homo-polymer.

The inductive effect due to electron-donating character of an alkoxy group present in 2,5-positions of phenylene ring would expect to contribute red shifting of absorption and emission maxima. Indeed, this effect is substantial in fluorescence but in absorption it contributes for blueshifting. It is attributed that although these alkoxy groups are positioned head-to-tail in adjacent rings but still yields a slightly greater preference for non-coplanar geometry in ground state. Thus, no shifting of absorption maxima on increasing the conjugation chain length can be rationalized by combining the total effect of alkoxy substituted phenylene with thiophene and chain extension. The absorption spectrum in methanol also shows similar spectral features. This indicates that polarity of the solvent does not influence the absorption property. Insolubility of the adduct (6) in common solvent (soluble only in DMSO) prohibits comparison of absorption property. UV-vis spectrum of (6) recorded in DMSO shows high absorption in UV-region and extended tailing in the entire visible region, typically matched with the characteristic of the fullerene derivatives (Figure 6).

\subsubsection{Emission Properties}

Comparative emission spectra of oligomer $\mathbf{5}$, fullerenol 
Table 1. Electrochemical data of oligomer 5.

\begin{tabular}{ccccccccc}
\hline & p-Doping $(\mathrm{V})$ & \multicolumn{3}{c}{ n-Doping $(\mathrm{V})$} & \multicolumn{3}{c}{ Energy Levels (eV) } \\
\hline$E_{\text {onset }}$ & $E_{\mathrm{pa}}$ & $E_{\mathrm{pc}}$ & $E_{\text {onset }}$ & $E_{\mathrm{pa}}$ & $E_{\mathrm{pc}}$ & HOMO & LUMO & Band Gap (eV) \\
1.47 & 1.55 & 1.42 & -0.66 & -0.77 & - & -5.87 & -3.74 & 2.13 \\
\hline
\end{tabular}

Table 2. Optical data of 4,5 and 6 .

\begin{tabular}{ccccc}
\hline & Abs. $\lambda_{\max }(\mathrm{nm})$ & Onset abs. $\lambda_{\text {onset }}(\mathrm{nm}) /$ band gap $(\mathrm{eV})$ & Emission $\lambda_{\mathrm{em}}(\mathrm{nm})$ & Stokes' shift(nm) \\
\hline $\mathbf{3 T}$ & $342 / 3.62$ & $433 / 2.86$ & & 91 \\
$\mathbf{4}$ & $300 / 4.13$ & $326 / 3.83$ & $502 / 2.48$ & 202 \\
$\mathbf{7 T}$ & $409 / 3.03$ & & $490 / 2.53$ & 81 \\
$\mathbf{5}$ & $302 / 4.10$ & $340 / 3.66$ & $512 / 2.43$ & 212 \\
$\mathbf{6}$ & entire UV & $461 / 2.7$ & $416 / 3.00436 / 2.86$ & \\
\hline
\end{tabular}

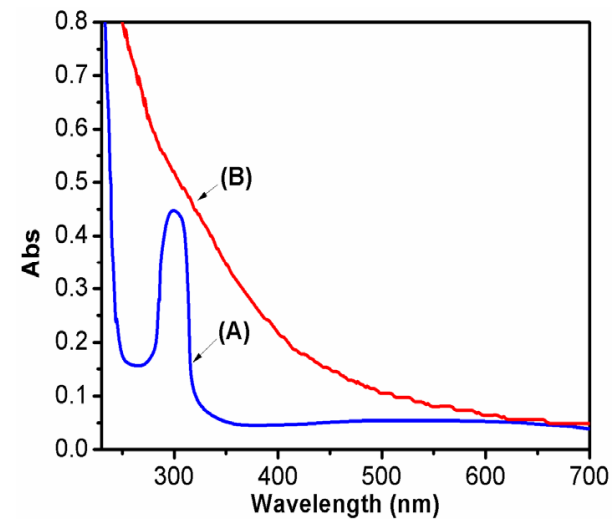

Figure 6. UV-vis spectra of (A) 5 and (B) 6 recorded in chloroform and DMSO respectively at room temperature.

and oligomer-fol adduct (6) measured in solid state using excitation wavelength $350 \mathrm{~nm}\left(\lambda_{\mathrm{ex}}=350 \mathrm{~nm}\right)$ are presented in Figure 7 and photophysical data are complied in Table 2. Fluorescence spectra of $\mathbf{5}$ show strong single emission peak in green region $(512 \mathrm{~nm} / 2.43 \mathrm{eV})$. A small red-shifting $(10 \mathrm{~nm})$ of emission peak in oligomer 5 compared to $\mathbf{4}$ is observed. It is attributed that this small red-shifting is net balance of two opposing factors operating simultaneously; the presence of phenyl ring in the backbone and contribution of thiophene ring and chain extension. However, both oligomer 5 and monomer 4 show a large Stokes' shift between absorption and emission peaks. The Stokes' shift is more than $200 \mathrm{~nm}$ and can be ascribed to the formation of more rigid planar inter-digited $\pi$-stack 3D structure and conformational symmetry occurring after photo-excitation [37-39] allowing a possible exciton migration to long conjugation segments. The large Stokes' shift of these materials thus promises a possible use as active medium in laser diodes.

Fullerene-diol and adduct 6 shows similar spectral pattern and the emission peaks appear at 416 and $436 \mathrm{~nm}$ in both the cases (Figure 7). Small perturbations of $\pi$ symmetry of fullerene in both fullerenol and adduct (6) result similar spectral patterns. Fullerene core governs the emission peaks positions and are independent of the nature of addends. Fluorescence intensity of the adduct (6) is however highly quenched compared to both fullerenol and oligomer (5) and is also blue shifted compared to oligomer 5. This indicates an efficient intra- and inter-molecular electron transfer from oligo-phenylenealt-thiophene (donor) to the fullerene (acceptor) producing a stable charge-transfer exciplex in photo-excited (Figure 8). Electron acceptor property of fullerene is well known and the functionalization with oligophenylenealt-thiophene molecules undergoes fast charge-separation (CS) and slow charge-recombination. [40] The stronger quenching in fluorescence intensity in $\mathrm{C}_{60}$-oligothiophene- $\mathrm{C}_{60}$ triads compared to oligo-thiophene- $\mathrm{C}_{60}$ dyads is observed earlier [41-45].

In addition, adduct (6) also show high blue-shift in photoluminescence spectra $(76 \mathrm{~nm})$ compared to $\mathbf{5}$. Conjugation defect and conformational disorder arises due to steric repulsion and distortion of torsional angle between phenylene-thiophene rings on chemical attachment of $\mathrm{C}_{60}$ results blue-shifting [33].

\subsection{Magnetic Properties}

Oligomer $\mathbf{5}$ in its pristine un-doped state is EPR inactive, indicating an absence of free $\operatorname{radical}(\mathrm{s}) / \mathrm{ion}(\mathrm{s})$ and electronically defect free symmetric structure in solid state. The oligomer behaves like a p-donor in presence of strong acceptor and creates an electronic imbalance within the adduct on chemical attachment to fullerene (acceptor) making it EPR active (Figure 9) [46]. Higher $g$-value $(g=2.005)$ compared to both free electron $(g=$ $2.0023)$ and fullerenol $(g=1.99)$ owing to strong electronic interaction between oligomer donor chain and 
fullerene acceptor producing resultant dipole moment within the dyad molecule. Deviation of g-factor from the free-spin value is a useful indication of the extent of spin-orbit coupling in the paramagnetic species and provides information about the molecular environment of the unpaired electrons. Absorption at higher magnetic field $(3515 \mathrm{G})$ compared to free electron $(3300 \mathrm{G})$ indicate electron-electron interaction within the molecule in ground state needing higher energy for electronic transition. Peak to peak width is inversely proportional to the spin-spin relaxation time $\left(T_{2}=1.31 \times 10^{-8} / g \cdot \Delta H_{p p}\right)$ which depends on the electron - electron interactions. For adduct 6, $T_{2}$ values are of the order of nanoseconds $\left(0.48 \times 10^{-9} \mathrm{~s}\right)$ and peak to peak width $\left(\Delta H_{p p}\right)$ is slightly broadened $\left(\Delta H_{p p}=13.8 \mathrm{G}\right)$. The higher peak width compared to pure fullerenol is due to the shorter lifetime of excited states and the molecule readily relax back to ground state

\section{Conclusion}

Bromo-end capped bis-(2,5-hexyloxy) substitutes phenylene-alt-thiophene oligomer and its attachment to fullerene-diol are explored for their thermal, electrochemical, photophysical and magnetic properties. Synthesis of oligomer and formation of its adduct with fullerenol are successfully carried out. Thermal disorder of oligomer on chemical attachment to fullerenol is evi- dent from the multi-step degradation of the adduct (6) compared to single step degradation in oligomer (5). Also, the chemical attachment induced paramagnetic character to otherwise EPR inactive material. Low bandgap of the oligomer in solution indicates symmetric planar structure and good electron donating contribution of alkoxy substituents towards easy migration of $\pi$-electrons. Attachment to fullerene moiety results partial distortion of co-planarity and is easily reflected from the

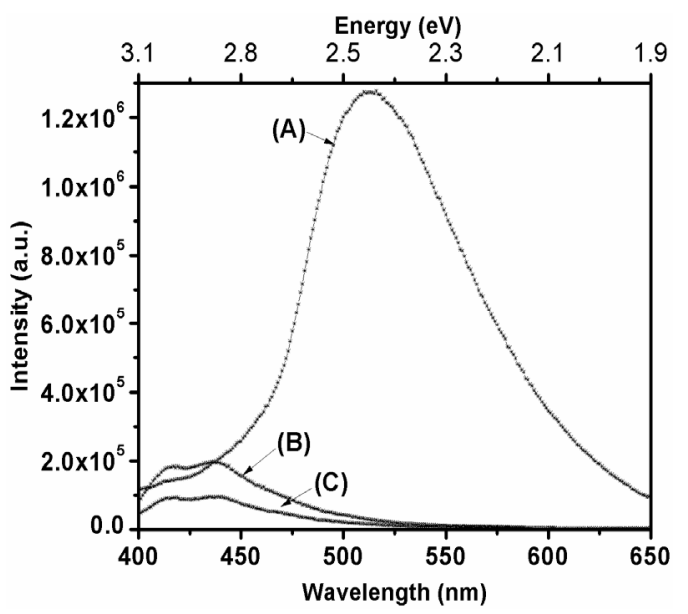

Figure 7. Comparative PL spectra of (A) oligomer 5, (B) $\mathrm{C}_{60}(\mathrm{OH})_{2}$ and $(\mathrm{C})$ adduct 6 using $350 \mathrm{~nm}$ excitation wavelength in solid state at room temperature.

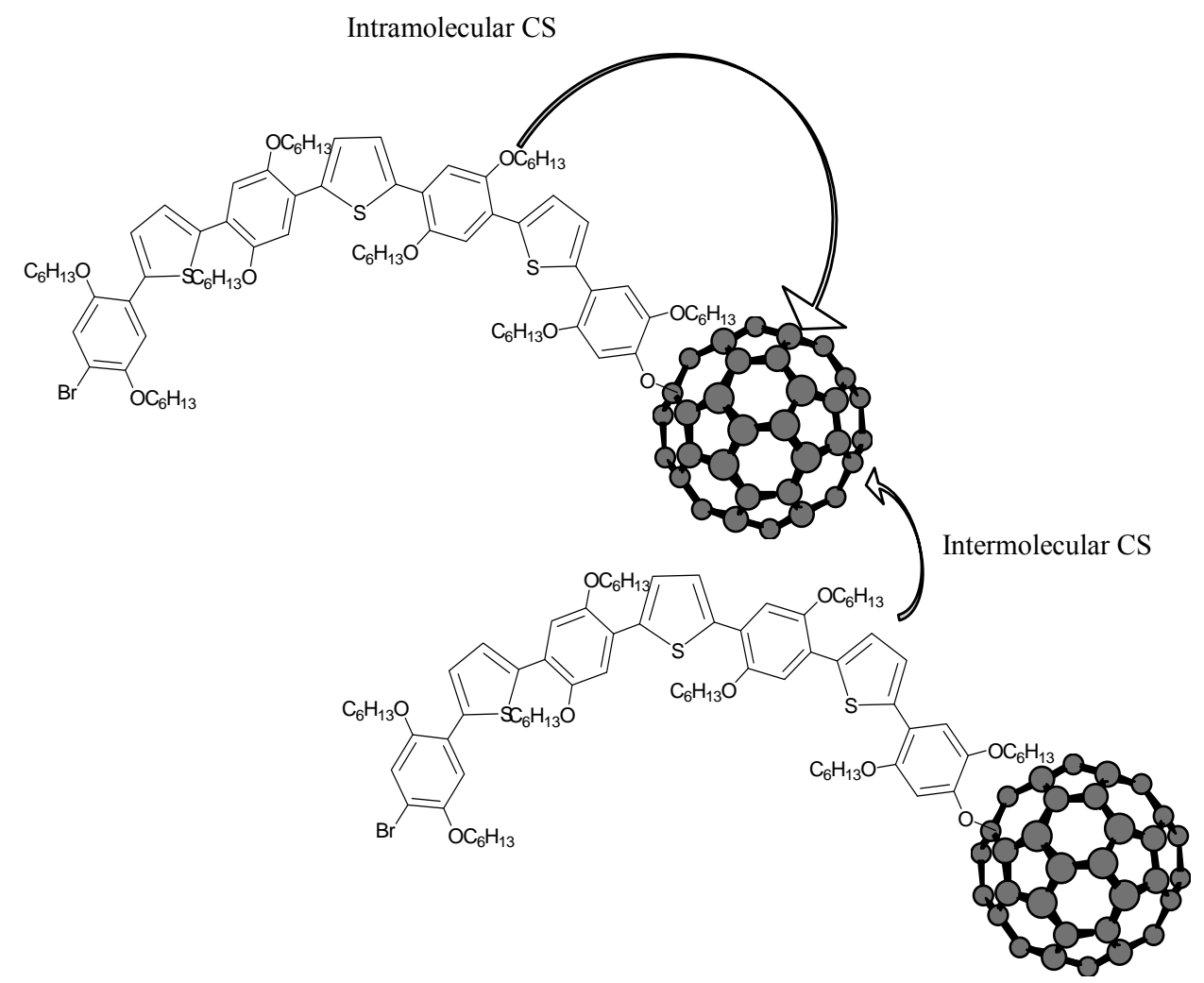

Figure 8. Schematic diagram of proposed intra- and intermolecular CS processes in 6. 


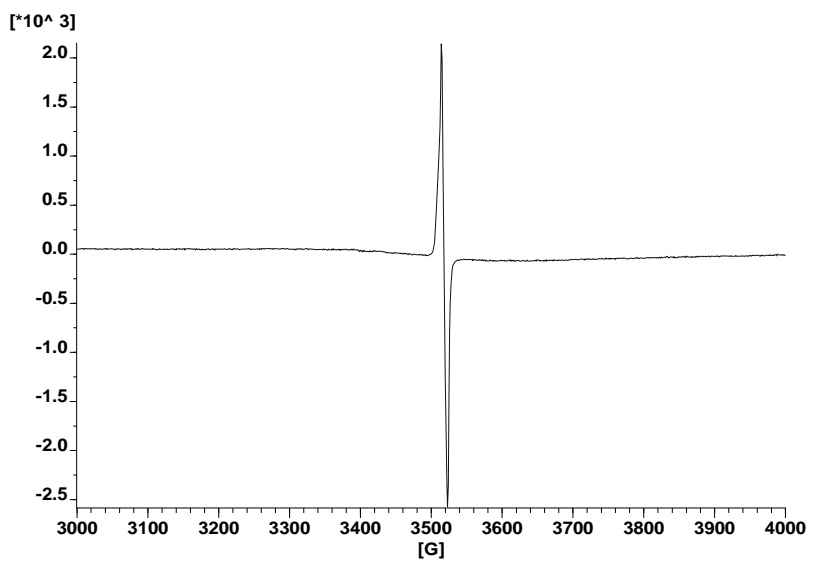

Figure 9. EPR spectra of adduct 6 recorded in solid at room temperature.

blue shifting of emission peak. There is considerable charge-transfer interaction between p-type oligomeric chain and n-type fullerene core resulting in the high quenching of fluorescence intensity. Optical properties of the polymer can be tuned by suitable manipulation of the back-bone chain and also by changing the substituents on both phenylene and thiophene rings. Long chain alkoxy pendant groups substantially improve the solubility yet contribute to retain rigid planar configuration in photoexcited state. These types of fullerene-addended materials may find potential in solar cells and photo-sensing devices.

\section{REFERENCES}

[1] J. Modin, H. Johansson and H. Grennberg, "New Pyrazolino- and Pyrrolidino[60]fullerenes with Transition-Metal Chelating Pyridine Substitutents: Synthesis and Complexation to Ru(II)," Organic Letters, Vol. 7, No. 18, 2005 , pp. 3977-3979. http://dx.doi.org/10.1021/ol051468f

[2] S. Campidelli, R. Deschenaux, A. Swartz, G. M. A. Rahman, D. M. Guldi, D. Milic, E. V'azquez and M. Prato, "A Dendritic Fullerene-Porphyrin Dyad," Photochemical \& Photobiological Sciences, Vol. 5, No. 12, 2006, pp. 1137-1141. http://dx.doi.org/10.1039/b610881d

[3] P. Vivo, M. Ojala, V. Chukharev, A. Efimov and H. Lemmetyinen, "Role of a Phthalocyanine-Fullerene Dyad in Multilayered Organic Solar Cells," Journal of Photochemistry and Photobiology A: Chemistry, Vol. 203, No. 2-3, 2009, pp. 125-130.

http://dx.doi.org/10.1016/j.jphotochem.2008.12.030

[4] J. Baffreau, L. Ordronneau, L. S. Leroy and P. Hudhomme, "Synthesis of Perylene-3,4-Mono(dicarboximide)-Fullerene $\mathrm{C}_{60}$ Dyads as New Light-Harvesting Systems," Journal of Organic Chemistry, Vol. 73, No. 16, 2008, pp. 6142. http://dx.doi.org/10.1021/jo800804z

[5] W. B. Zhang, Y. Tu, R. Ranjan, R. M. V. Horn, S. Leng, J. Wang, M. J. Polce, C. Wesdemiotis, R. P. Quirk, G. R. Newkome and S. Z. D. Cheng, "Clicking Fullerene with Polymers: Synthesis of [60]Fullerene End-Capped Poly- styrene," Macromolecules, Vol. 41, No. 3, 2008, pp. 515517. http://dx.doi.org/10.1021/ma702345r

[6] C. Wang, Z. X. Guo, S. Fu, W. Wu and D. Zhu, "Polymers Containing Fullerene or Carbon Nanotube Structures," Progress in Polymer Science, Vol. 29, No. 11, 2004, p. 1079-1141. http://dx.doi.org/10.1016/j.progpolymsci.2004.08.001

[7] A. L. Ortiz, D. M. Rivera, A. J. Athans and L. Echegoyen, "Regioselective Addition of $\mathrm{N}$-(4-Thiocyanatophenyl)pyrrolidine Addends to Fullerenes," European Journal of Organic Chemistry, 2009, p. 3396.

[8] Z. Zhou, G. H. Sarova, S. Zhang, Z. Ou, F. T. Tat, K. M. Kadish, L. Echegoyen, D. M. Guldi, D. I. Schuster and S. R. Wilson, "Fullerene Polypyridine Ligands: Synthesis, Ruthenium Complexes, and Electrochemical and Photophysical Properties," Chemistry-A European Journal, Vol. 12, No. 16, 2006, pp. 4241-4248. http://dx.doi.org/10.1002/chem.200600021

[9] R. Singh and T. H. Goswami, "Photophysical and Optical Limiting Properties of Multifunctional Hemi-Ortho Ester Derivatives of Fullerenol: Effects of TBAH Doping, Fullerenol Concentration and Solvent Polarity," Synthetic Metals, Vol. 161, No. 9-10, 2011, pp. 670-679. http://dx.doi.org/10.1016/j.synthmet.2011.01.012

[10] R. Singh and T. H. Goswami, "Effect of Nature of Addends and Ionic Dopant on Magnetic Properties of Multifunctional Star-Like Hemi-Ortho Ester Derivatives of Fullerenol," Synthetic Metals, Vol. 161, No. 19-20, 2011, pp. 2070-2077. http://dx.doi.org/10.1016/j.synthmet.2011.07.015

[11] R. Singh and T. H. Goswami, "Highly Luminescent Multifunctional Hemi-Ortho Ester Derivatives of Fullerenol," Synthetic Metals, Vol. 157, No. 22-23, 2007, pp. 951-955. http://dx.doi.org/10.1016/i.synthmet.2007.09.006

[12] R. Singh and T. H. Goswami, "Understanding of ThermoGravimetric Analysis to Calculate Number of Addends in Multifunctional Hemi-Ortho Ester Derivatives of Fullerenol," Thermochim Acta, Vol. 513, No. 1-2, 2011, pp. 6067. http://dx.doi.org/10.1016/j.tca.2010.11.012

[13] R. Singh and T. H. Goswami, "Synthesis and Evaluation of Thermal, Photophysical and Magnetic Properties of Novel Starlike Fullerene-Organosilane Macromolecules," Journal of Organometallic Chemistry, Vol. 693, No. 11, 2008, pp. 2021-2032. http://dx.doi.org/10.1016/j.jorganchem.2008.03.006

[14] R. Singh and T. H. Goswami, "Acid Catalyzed 1,2 Michael Addition Reaction: A Viable Synthetic Route in Designing Fullerene Core Starlike Macromolecule," Journal of Physical Organic Chemistry, Vol. 21, No. 3, 2008, pp. 225-236. http://dx.doi.org/10.1002/poc.1304

[15] T. H. Goswami and R. Singh, "Recent Development of Fullerenol Reseach," In: C. N. Kramer, Ed., Fullerene Research Advances, NOVA Science Publishers, New York, 2007, pp. 55-96.

[16] R. Singh and T. H. Goswami, "Thermal Analysis: A Unique Method to Estimate the Number of Substituents in Fullerene Derivatives," Thermochim Acta, Vol. 419, No. 1-2, 2004, pp. 97-104. http://dx.doi.org/10.1016/j.tca.2004.02.001 
[17] T. H. Goswami, B. Nandan, S. Alam and G. N. Mathur, "A Selective Reaction of Polyhydroxy Fullerene with Cycloaliphatic Epoxy Resin in Designing Ether Connected Epoxy Star Utilizing Fullerene as a Molecular Core," Polymer, Vol. 44, No. 11, 2003, pp. 3209-3214. http://dx.doi.org/10.1016/S0032-3861(03)00241-6

[18] T. H. Goswami, R. Singh, S. Alam and G. N. Mathur, "One-Pot Synthesis of a Novel Water-Soluble FullereneCore Starlike Macromolecule via Successive Michael and Nucleophilic Addition Reaction," Chemical Materials, Vol. 16, No. 12, 2004, pp. 2442-2448. http://dx.doi.org/10.1021/cm0350232

[19] M. S. Meier and J. Kiegiel, "Preparation and Characterization of the Fullerene Diols 1,2- $\mathrm{C}_{60}(\mathrm{OH})_{2}, 1,2-\mathrm{C}_{70}(\mathrm{OH})_{2}$, and 5,6- $\mathrm{C}_{70}(\mathrm{OH})_{2}$," Organic Letters, Vol. 3, No. 11, 2001, pp. 1717-1719. http://dx.doi.org/10.1021/ol0159120

[20] R. H. Lohwasser, J. Bandara and M. Thelakkat, "TailorMade Synthesis of Poly(3-hexylthiophene) with Carboxylic Endgroups and Its Application as a Polymer Sensitizer in Solid-State Dye-Sensitized Solar Cells," Journal of Materials Chemistry, Vol. 19, 2009, pp. 4126-4130. http://dx.doi.org/10.1039/b900921c

[21] J. U. Lee, A. Cirpan, T. Emrick, T. P. Russell and W. H. Jo, "Synthesis and Photophysical Property of Well-Defined Donor-Acceptordiblock Copolymer Based on Regioregular Poly(3-hexylthiophene) and Fullerene," Journal of Materials Chemistry, Vol. 19, 2009, pp. 1483-1489. http://dx.doi.org/10.1039/b813368a

[22] C. P. Chen, S. H. Chan, T. C. Chao, C. Ting and B. T. Ko, "Low-Bandgap Poly(Thiophene-Phenylene-Thiophene) Derivatives with Broaden Absorption Spectra for Use in High-Performance Bulk-Heterojunction Polymer Solar Cells," Journal of the American Chemical Society, Vol. 130, No. 38, 2008, pp. 12828-12833. http://dx.doi.org/10.1021/ja801877k

[23] M. L. Blohm, J. E. Pikett and P. C. VanDort, "Synthesis, Characterization, and Stability of Poly(3,4-Dibutoxythiophenevinylene) Copolymers," Macromolecules, Vol. 26, No. 11, 1993, pp. 2704-2710. http://dx.doi.org/10.1021/ma00063a011

[24] S. A. Chen and C. C. Tsai, "Structure/Properties of Conjugated Conductive Polymers. 2. 3-Ether-Substituted Polythiophenes and Poly(4-Methylthiophenes)," Macromolecules, Vol. 26, No. 9, 1993, pp. 2234-2239.

http://dx.doi.org/10.1021/ma00061a015

[25] G. Gigli, G. Barbarella, L. Favaretto, F. Cacialli and R. Cingolani, "High-Efficiency Oligothiopene-Based LightEmitting Diodes," Applied Physics Letters, Vol. 75, 1999, p. 439. http://dx.doi.org/10.1063/1.124403

[26] J. L. Bredas, R. Silbey, D. S. Boudreaux and R. R. Chance, "Chain-Length Dependence of Electronic and Electrochemical Properties of Conjugated Systems: Polyacetylene, Polyphenylene, Polythiophene, and Polypyrrole," Journal of the American Chemical Society, Vol. 105, No. 22, 1983, pp. 6555-6559. http://dx.doi.org/10.1021/ja00360a004

[27] D. M. de Leeuw, M. M. Simenon, A. R. Brown and R. E. F. Einerhand, "Stability of N-Type Doped Conducting Polymers and Consequences for Polymeric Microelec- tronic Devices," Synthetic Metals, Vol. 87, No. 1, 1997, pp.53-59.

http://dx.doi.org/10.1016/S0379-6779(97)80097-5

[28] S. A. Ponomarenko, S. Kirchmeyer, A. Elschner, N. M. Alpatova, M. Halik, H. Klauk, U. Zschieschang and G. Schmid, "Decyl-End-Capped Thiophene-Phenylene Oligomers as Organic Semiconducting Materials with Improved Oxidation Stability," Chemical Materials, Vol. 18, No. 2, 2006, pp. 579-586.

http://dx.doi.org/10.1021/cm052210m

[29] S. Mohapatra, B. T. Holmes, C. R. Newman, C. F. Prendergast, C. D. Frisbie and M. D. Ward, "Organic ThinFilm Transistors Based on Tolyl-Substituted Oligothiophenes," Advanced Functional Materials, Vol. 14, No. 6, 2004, pp. 605-609. http://dx.doi.org/10.1002/adfm.200400034

[30] Q. Zhang, J. Feng, K. Liu, D. Zhu, M. Yang, H. Ye and X. Liu, "Synthesis and Characterization of Novel Low Band Gap Polymers: Poly(heteroarylene methines)," Synthetic Metals, Vol. 156, No. 11-13, 2006, pp. 804-808. http://dx.doi.org/10.1016/j.synthmet.2006.04.014

[31] G. Louarn, J. Y. Mevellec, J. P. Buisson and S. Lefrant, "Experimental Ant Theoretical Study of Vibrational Properties of Polythiophène, Polyméthylthiophène and Polyoctylthiophène," Journal de Chimie Physique, Vol. 89, 1992, p. 987.

[32] J. F. Pan, S. J. Chua and W. Huang, "Conformational Analysis (ab Initio HF/3-21G*) and Optical Properties of Poly(thiophene-phenylene-thiophene) (PTPT)," Chemical Physics Letters, Vol. 363, No. 1-2, 2002, pp. 18-24. http://dx.doi.org/10.1016/S0009-2614(02)00934-X

[33] J. Pei, W. L. Yu, W. Huang and A. J. Heeger, "A Novel Series of Efficient Thiophene-Based Light-Emitting Conjugated Polymers and Application in Polymer LightEmitting Diodes," Macromolecules, Vol. 33, No. 7, 2000, pp. 2462-2471. http://dx.doi.org/10.1021/ma9914220

[34] F. Naso, F. Babudri, D. Colangiuli, G. M. Farinola, F. Quaranta, R. Rella, R. Tafuro and L. Valli, "Thin Film Construction and Characterization and Gas-Sensing Performances of a Tailored Phenylene-Thienylene Copolymer," Journal of the American Chemical Society, Vol. 125, No. 30, 2003, pp. 9055-9061. http://dx.doi.org/10.1021/ja035490k

[35] S. J. Toal and T. C. Williams, "Polymer Sensors for Nitroaromatic Explosives Detection," Journal of Materials Chemistry, Vol. 16, 2006, pp. 2871-2883. http://dx.doi.org/10.1039/b517953j

[36] F. Meyer, A. J. Heeger and J. L. Bredas, "Fine Tuning of the Band Gap in Conjugated Polymers via Control of Block Copolymer Sequences," The Journal of Chemical Physics, Vol. 97, No. 4, 1992, p. 2750. http://dx.doi.org/10.1063/1.463065

[37] M. A. Loi, E. J. W List, C. Gadermaier, W. Graupner, G. Leising, G. Bongiovanni, A. Mura, J. J. Pireaux and K. Kaeriyama, "Optical Characterisation of Poly-2,5-diheptyl1,4-phenylene-alt-2,5-Thienylene," Synthetic Metals, Vol. 111-112, 2000, pp. 519-522. http://dx.doi.org/10.1016/S0379-6779(99)00410-5

[38] R. A. J Janssen, L. Smilowitz, N. S. Sariciftci and D. 
Moses, "Triplet-State Photoexcitations of Oligothiophene Films and Solutions," The Journal of Chemical Physics, Vol. 101, No. 3, 1994, p. 1787. http://dx.doi.org/10.1063/1.467757

[39] G. Lanzzni, M. Nisoli, V. Magni, S. De Silvestri, G. Barbarella, M. Zambianchi and R. Tubino, "Femtosecond Spectral Relaxation of $\alpha$-Conjugated Hexamethylsexithiophene in Solution," Physical Review B, Vol. 51, No. 19, 1995, pp. 13770-13773. http://dx.doi.org/10.1103/PhysRevB.51.13770

[40] P. A. Liddell, J. P. Sunida, A. N. McPherson, L. Noss, G. R. Seely, K. N. Clark, A. L. Moore, T. A. Moore and D. Gust, "Preparation and Photophysical Studies of Porphyrin- $\mathrm{C}_{60}$ Dyads," Photochemistry and Photobiology, Vol. 60, No. 6, 1994, pp. 537-541. http://dx.doi.org/10.1111/j.1751-1097.1994.tb05145.x

[41] C. H. Lee, G. Yu, D. Moses, N. S. Sariciftci and A. J. Heeger, "Sensitization of the Photoconductivity of Conducting Polymers by $\mathrm{C}_{60}$ : Photoinduced Electron Transfer," Physical Review B, Vol. 48, No. 20, 1993, pp. 1542515433. http://dx.doi.org/10.1103/PhysRevB.48.15425

[42] C. H. Lee, A. J. Janssen, N. S. Sariciftci and A. J. Heeger, "Direct Evidence of Photoinduced Electron Transfer in Conducting-Polymer- $\mathrm{C}_{60}$ Composites by Infrared Photoexcitation Spectroscopy," Physical Review B, Vol. 49, No.
8, 1994, pp. 5781-5784. http://dx.doi.org/10.1103/PhysRevB.49.5781

[43] N. Negishi, K. Yamada, K. Takimiya, Y. Aso, T. Otsubo and Y. Harima, "Oligothiophene/Fullerene Dyads as Active Photovoltaic Materials," Chemistry Letters, Vol. 32, No. 4, 2003, pp. 404-405.

http://dx.doi.org/10.1246/cl.2003.404

[44] N. Negishi, K. Takimiya, T. Otsubo, Y. Harima and Y. Aso, "Synthesis and Photovoltaic Effects of Oligothiophenes Incorporated with Two [60]Fullerenes," Chemistry Letters, Vol. 33, No. 6, 2004, pp. 654-655. http://dx.doi.org/10.1246/c1.2004.654

[45] J. F. Nierengarten, "Fullerene-( $\pi$-Conjugated Oligomer) Dyads as Active Photovoltaic Materials," Solar Energy Materials \& Solar Cells, Vol. 83, No. 2-3, 2004, pp. $187-$ 199. http://dx.doi.org/10.1016/j.solmat.2004.02.024

[46] S. B. Lee, A. A. Zakhidov, I. I. Khairullin, V. Y. Sokolov, P. K. Khabibullaev, K. Tada, K. Yashimoto and K. Yoshino, "Ground State Charge Transfer in Fullerene-Polyalkylthiophene Composites: ESR and Iodine Doping Effect," Synthetic Metals, Vol. 77, No. 1-3, 1996, pp. 155159. http://dx.doi.org/10.1016/0379-6779(96)80078-6 


\section{Supporting Information}

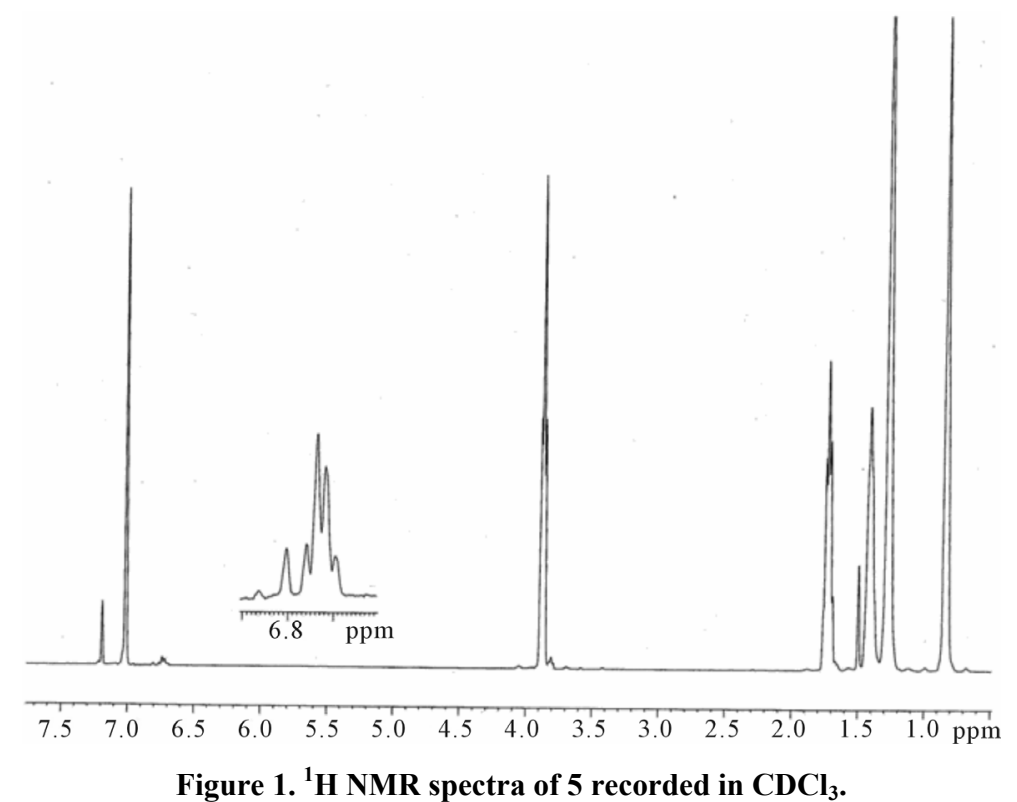

Figure 1. ${ }^{1} \mathrm{H}$ NMR spectra of 5 recorded in $\mathrm{CDCl}_{3}$.

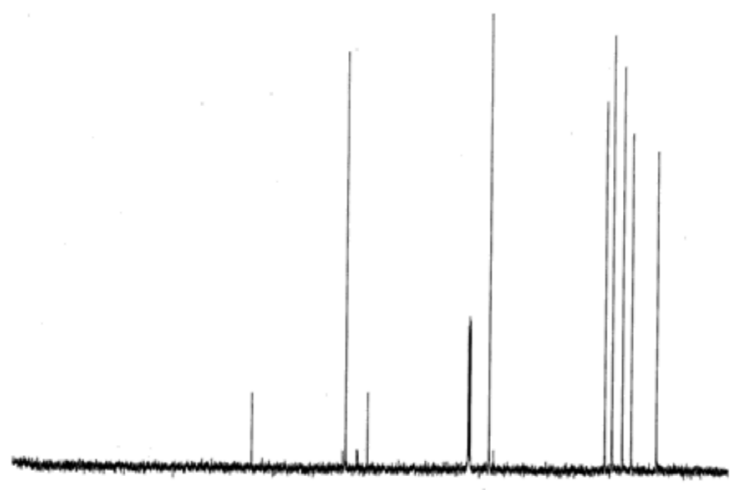

$\begin{array}{lllllllllllll}220 & 200 & 180 & 160 & 140 & 120 & 100 & 80 & 60 & 40 & 20 & \mathrm{ppn}\end{array}$

Figure 2. ${ }^{13} \mathrm{C}$ NMR spectra of 5 recorded in $\mathrm{CDCl}_{3}$.

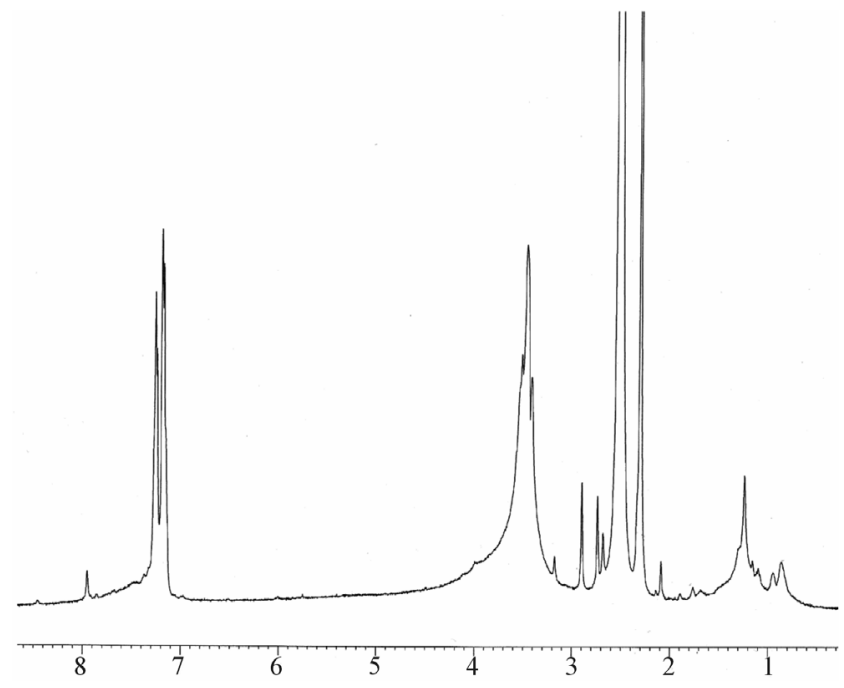

Figure 3. ${ }^{1} \mathrm{H}$ NMR spectra of 6 recorded in DMSO. 


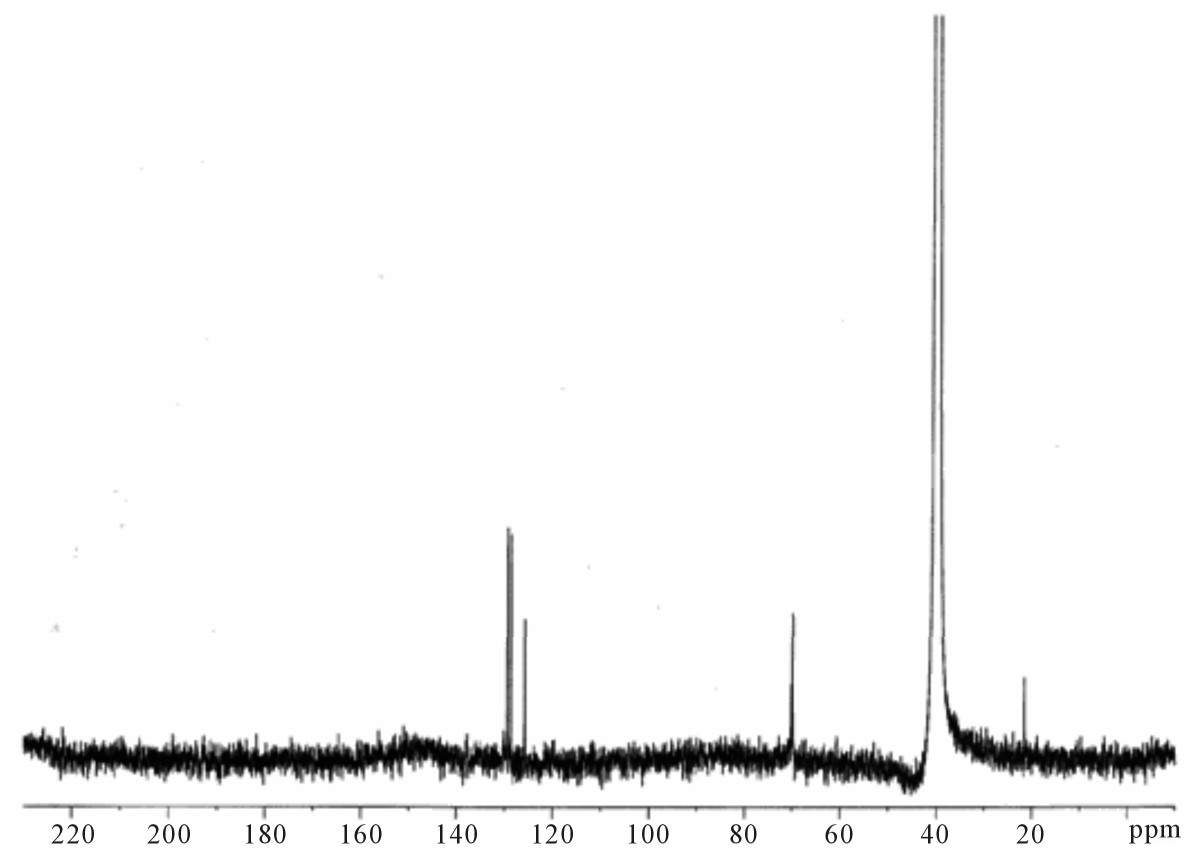

Figure 4. ${ }^{13} \mathrm{C}$ NMR spectra of 6 recorded in DMSO.

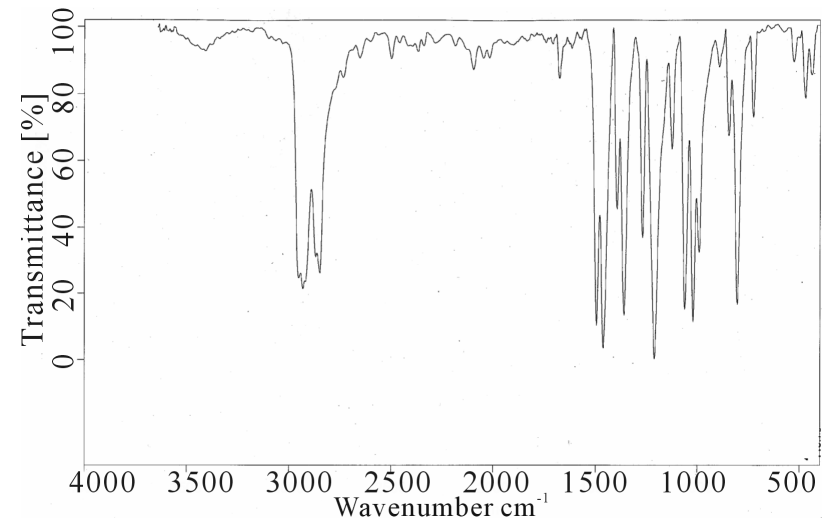

Figure 5. FTIR spectra of 5.

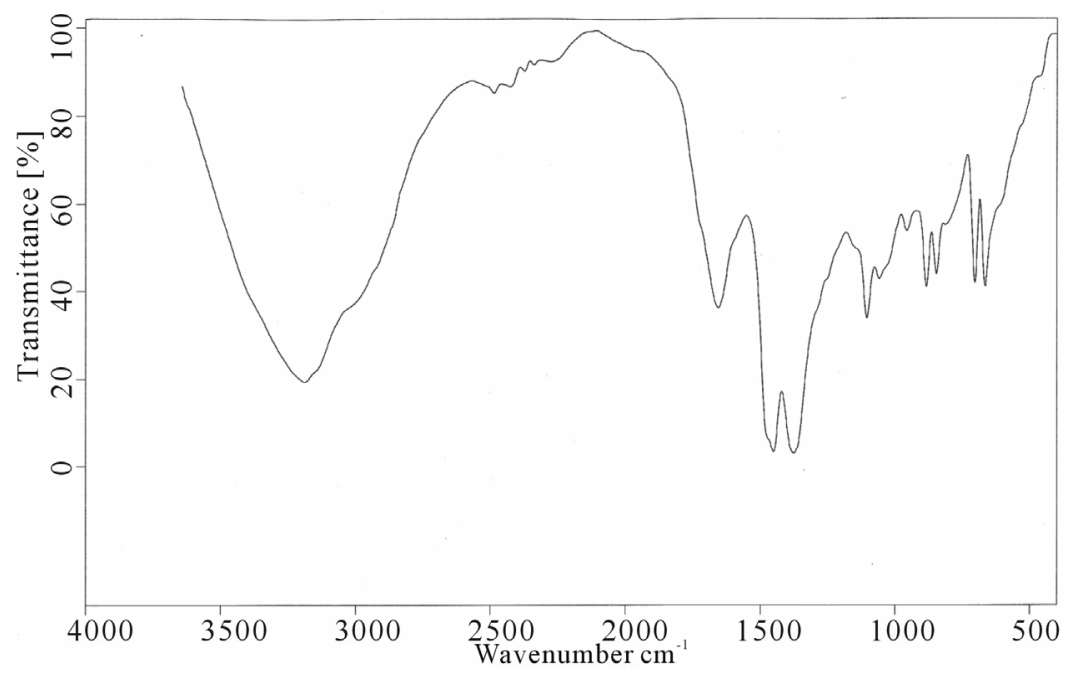

Figure 6. FTIR spectra of 6. 


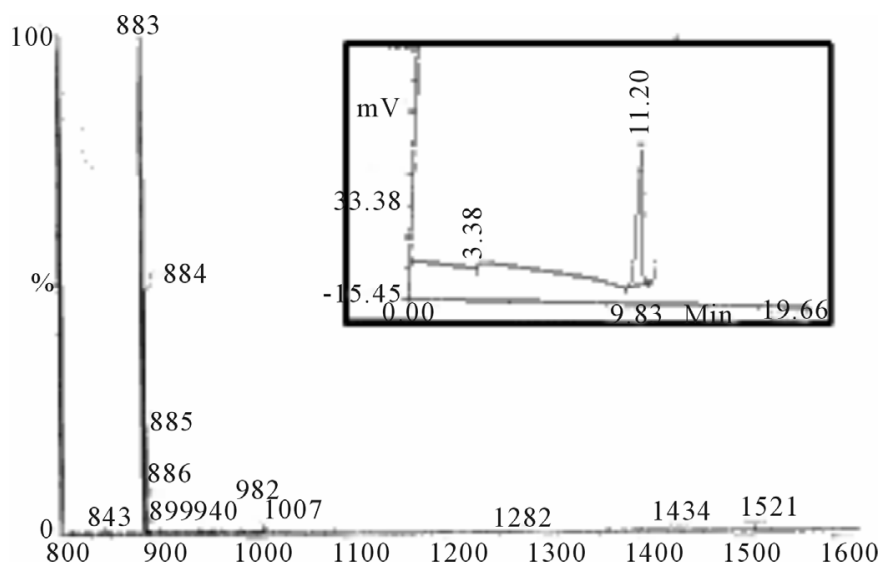

Figure 7. ESIMS spectra of 5 recorded in methanol. Inset showing the GPC chromatogram with molecular weight about 1520.

Table 1. Details of ${ }^{1} \mathrm{H} \&{ }^{13} \mathrm{C}$ NMR peak assignment.

\begin{tabular}{|c|c|c|}
\hline Sample & ${ }^{1} \mathrm{H}$ peak Assigned ${ }^{13} \mathrm{C}$ Peak & Assigned \\
\hline Code & position proton position & carbon \\
\hline \multirow[t]{7}{*}{4} & $6.9{ }_{3} \mathrm{H}(\mathrm{Ph})$ & $119.4{ }_{1} \mathrm{C}(\mathrm{Ph})$ \\
\hline & $6.8{ }_{6} \mathrm{H}(\mathrm{Ph})$ & $148_{2 / 5} \mathrm{C}(\mathrm{Ph})$ \\
\hline & $7.09{ }_{3} \mathrm{H}(\mathrm{Th})$ & $118{ }_{3} \mathrm{C}(\mathrm{Ph})$ \\
\hline & & $111{ }_{4} \mathrm{C}(\mathrm{Ph})$ \\
\hline & & $114{ }_{6} \mathrm{C}(\mathrm{Ph})$ \\
\hline & & $138_{2 / 5} \mathrm{C}(\mathrm{Th})$ \\
\hline & & $128_{3 / 4} \mathrm{C}(\mathrm{Th})$ \\
\hline \multirow[t]{8}{*}{5} & $6.7-6.8(\mathrm{~m}) \mathrm{Ph}, \mathrm{Th}$ & $111{ }_{4} \mathrm{C}-\mathrm{Br}$ \\
\hline & 7.01 & $112{ }_{3} \mathrm{C}($ inner $\mathrm{Ph})$ \\
\hline & & $114{ }_{6} \mathrm{C}$ (terminal $\left.\mathrm{Ph}\right)$ \\
\hline & & $118{ }_{3} \mathrm{C}(\mathrm{Ph})$ \\
\hline & & $119{ }_{1} \mathrm{C}(\mathrm{Ph})$ \\
\hline & & $150{ }_{2} \mathrm{C}(\mathrm{Ph})$ \\
\hline & & $153{ }_{5} \mathrm{C}(\mathrm{Ph})$ \\
\hline & & $138_{2 / 3} \mathrm{C}(\mathrm{Th})$ \\
\hline \multirow[t]{10}{*}{6} & $0.8-1.0 \mathrm{CH}_{3}$ & $29-69 \mathrm{C}_{6} \mathrm{H}_{13}$ \\
\hline & $1.15-1.23 \mathrm{CH}_{3} \mathrm{CH}_{2}$ & $76.7 \mathrm{sp}^{3}$ fullerene \\
\hline & $1.6 \mathrm{CH}_{2}$ & $125.6{ }_{1} \mathrm{C} \&{ }_{4} \mathrm{C}$ of inner $\mathrm{Ph}$ \\
\hline & $2.3 \mathrm{CH}_{2}$ & $28.5_{3 / 4} \mathrm{C}(\mathrm{Th})$ \\
\hline & $3.4-3.5 \mathrm{O}^{-\mathrm{CH}_{2}}$ & 129.2 ${ }_{4} \mathrm{C}$ - $\mathrm{Ph}$ attached to $\mathrm{C}_{60}$ \\
\hline & $7.16-7.18 \mathrm{Th}$ & $130.08{ }_{2} \mathrm{C} \&{ }_{5} \mathrm{C} \mathrm{Th}$ \\
\hline & $7.23-7.25 \mathrm{Ph}$ & $148{ }_{2} \mathrm{C} \&{ }_{5} \mathrm{C} \mathrm{Ph}$ \\
\hline & & $150.4{ }_{2} \mathrm{C}$ terminal $\mathrm{Ph}$ \\
\hline & & $150.9{ }_{5} \mathrm{C}-\mathrm{Ph}$ attached to $\mathrm{C}_{60}$ \\
\hline & & $156.2{ }_{4} \mathrm{C}-\mathrm{O}$ \\
\hline
\end{tabular}




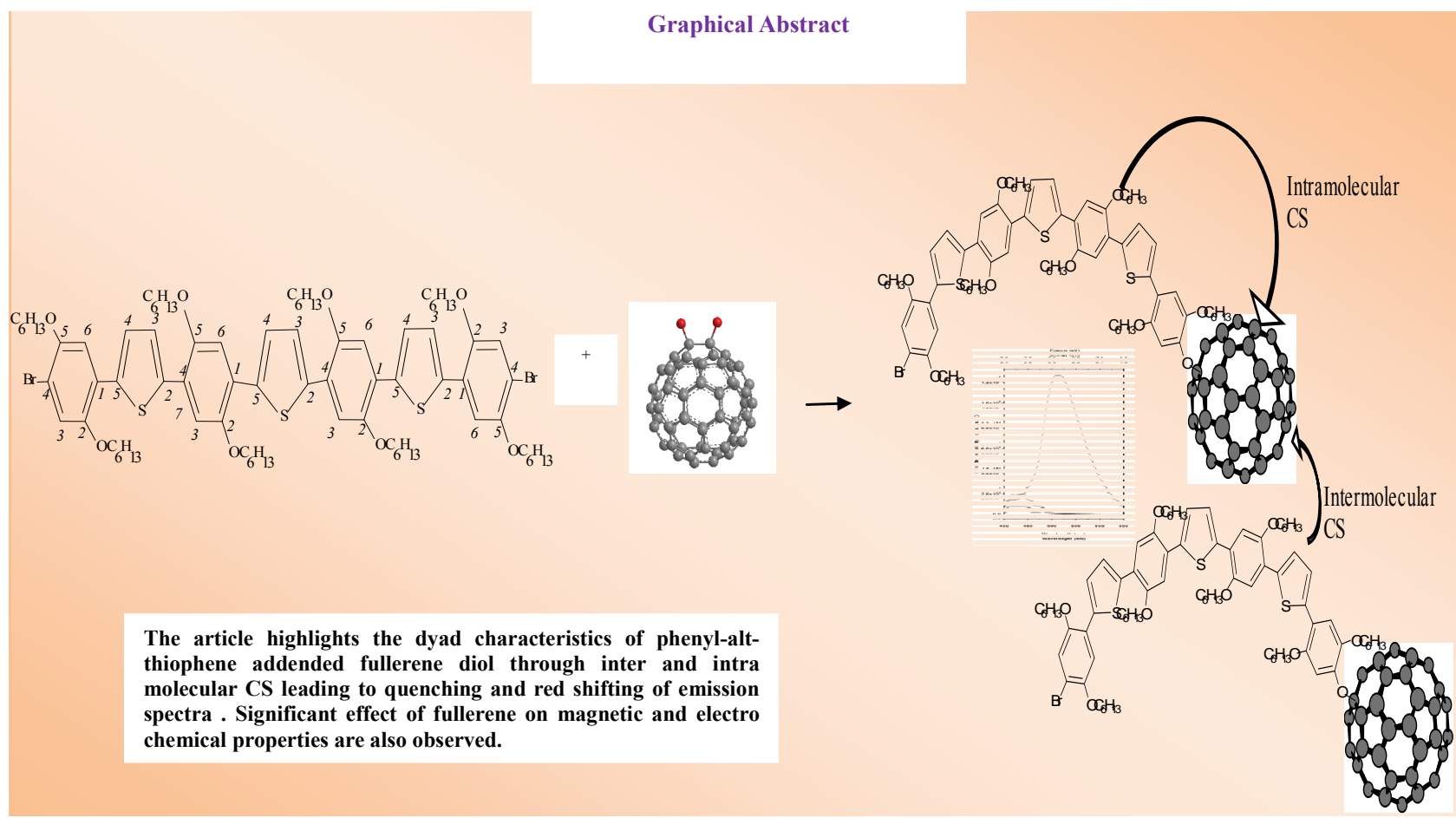

